\title{
Math Performance and Academic Anxiety Forms, from Sociodemographic to Cognitive Aspects: a Meta-analysis on 906,311 Participants
}

\author{
Sara Caviola ${ }^{1,2}$ (D) Enrico Toffalini ${ }^{3}$ - David Giofrè ${ }^{4}$ - Jessica Mercader Ruiz ${ }^{5}$. \\ Dénes Szűcs ${ }^{6}$ Irene C. Mammarella ${ }^{1}$
}

Accepted: 14 May 2021 /Published online: 4 August 2021

(C) The Author(s) 2021

\begin{abstract}
The relationship between anxiety and mathematics has often been investigated in the literature. Different forms of anxiety have been evaluated, with math anxiety (MA) and test anxiety (TA) consistently being associated with various aspects of mathematics. In this meta-analysis, we have evaluated the impact of these forms of anxiety, distinguishing between different types of mathematical tasks. In investigating this relationship, we have also included potential moderators, such as age, gender, working memory, type of task, and type of material. One hundred seventy-seven studies met the inclusion criteria, providing an overall sample of 906,311 participants. Results showed that both MA and TA had a significant impact on mathematics. Sociodemographic factors had modest moderating effects. Working memory (WM) also mediated the relationship between MA and TA with mathematics; however, this indirect effect was weak. Theoretical and educational implications, as well as future directions for research in this field, are discussed.
\end{abstract}

Keywords Mathematics performance $\cdot$ Math anxiety $\cdot$ Test anxiety $\cdot$ Working memory $\cdot$ Metaanalysis

\section{Introduction}

During school years, many students experience feelings of apprehension and fear brought on by testing situations or by facing a particularly challenging subject, such as math (Aiken, 1970; Cassady, 2010; Foley et al., 2017). These negative emotional reactions can ultimately decrease academic performance and can even impact individual aspirations and choices later in life (Hembree, 1990). In the last century, extensive research in both the educational and

Sara Caviola

sara.caviola@unipd.it

Extended author information available on the last page of the article 
psychological fields has been devoted to providing a better understanding and classification of these negative reactions, which are generally referred to as "academic anxieties". Within a school setting, the two most studied forms of academic anxiety are math anxiety and test anxiety (Cassady, 2010). These two forms of anxiety are multidimensional and involve cognitive, bodily, affective, and behavioural responses associated with concerns about possible negative consequences of failure (Mammarella et al., 2019; Zeidner, 2007).

Math anxiety (hereafter MA) refers to negative feelings of tension and apprehension experienced when thinking about and performing mathematical problems or number-related tasks in both academic situations and ordinary life (Ashcraft, 2002), and is often associated with disengagement and low achievement (see Moore et al. (2015), and Mammarella et al. (2019) for a comprehensive review). MA is a widespread phenomenon that impacts mathematical learning across the globe; 65 countries participated in the Program for International Student Assessment (PISA), in which 33\% of students reported that they experience a feeling of helplessness when solving mathematical problems. Furthermore, an examination of OECD countries revealed that $14 \%$ of the variation in math performance was explained by variations in MA, and that even on controlling for the effects of gender and socioeconomic status, the association between MA and math performance was robust (OECD, 2013, 2016).

The other form of academic anxiety linked to a school context is test anxiety (TA). TA can be considered a form of anxiety in educational settings, encompassing affective, cognitive, and physiological reactions that are usually experienced during exams or similar evaluative situations (Sieber et al., 1977; Zeidner, 2007). TA can be defined by negative cognitions or worries (e.g. unwanted, uncontrollable, and negative thoughts), as well as by an autonomic arousal or emotionality (i.e. physiological responses such as muscular tension, elevated heart rate, sweating, feeling sick, and shaking) (Liebert \& Morris, 1967). The negative influence of TA is concerning for educators, given the high prevalence (among students within typical academic settings; Gerwing et al., 2015) of anxiety at levels that hinder performance. Researchers have suggested that the increase in school testing to meet rising standards has likely led to the perception of tests as threatening, thus increasing the experience of TA (Von Der Embse et al., 2013). More recently, Putwain and Daly (2014) estimated that " $16.4 \%$ of participants reported themselves as being in the high range of test anxiety scores" (p. 564), whereas debilitating levels of TA were reported by approximately $15 \%$ of students within assessment contexts, based on a sample of more than 2400 UK secondary school students (age 14-16). These indicative numbers show that TA is an important issue; however, the specific incidence can vary greatly between published studies, as there is little agreement as to what constitutes "high" or "clinically significant" levels of TA. As noted by Ross and colleagues (Roos et al., 2020), a certain level of uncertainty comes also from self-report assessments typically used to measure TA (as well as MA), which can be biased by aspects such as social desirability or subjective beliefs (Goetz et al., 2013; Pekrun \& Bühner, 2014), thus not exactly reflecting the actual level of TA. Furthermore, other uncontrolled factors such as different ethnic backgrounds may influence TA intensity (Putwain, 2007).

Despite the uniqueness of MA and TA as specialized forms of anxiety, both share common features, including a perceived risk of failure and resultant disapproval by significant others who are evaluating the performance in comparison to a standard of achievement (Zeidner, 2014). Furthermore, both MA and TA share similar cognitive and physiological components of anxiety, such as sweating and increased heart rate (Liebert \& Morris, 1967; Ma, 1999; Wigfield \& Meece, 1988). Although it is generally stated that MA is, in fact, a separate construct from TA (Hembree, 1990), in the present meta-analysis, we estimated MA or TA 
relationship with math performance and analyzed the effect of several potential variables (such as gender, age, types of math, and working memory tasks) that could moderate the relationship between MA or TA and math performance.

\section{Academic Anxiety and Math Performance: Type of Math Tasks and Demographic Variables}

As previously mentioned, both forms of academic anxiety (MA and TA) are far-reaching and tend to have a detrimental impact on academic performance (Hembree, 1990; Ma, 1999; Putwain, 2008; Segool et al., 2013). In the present meta-analysis, we have specifically focused on mathematic performance; however, it is also important to consider that mathematics is not a unitary domain (Dowker, 2015). Rather, mathematical skills can be grouped into different spheres (e.g. arithmetic, geometry), each including different sub-components (e.g. magnitude representations, counting, retrieving arithmetic facts, understanding shapes, and handling data) (Dowker, 2005, 2015). Previous studies assessed mathematics achievement using various tests, each drawing on a different repertoire of mathematical sub-components with different degrees of complexity. Importantly, some of these tests rely heavily on basic numerical skills, such as magnitude comparison tasks (Schneider et al., 2017), while others focused on specific algorithms (Caviola et al., 2018). Lastly, some tests are widely-used curriculum-based standardized batteries, aimed at assessing overall math achievement according to a targeted level of education (i.e. the Woodcock-Johnson IV Tests of Achievement as described by Schrank et al., 2014). Thus, it is important to elucidate how MA and TA affect mathematics performance by considering different mathematical sub-domains as well as any variables that may influence this relationship.

\section{Math Anxiety}

MA, by its own definition, has a specific negative impact on an individual's math achievement (Ashcraft \& Moore, 2009; Miller \& Bichsel, 2004; Núñez-Peña et al., 2013). As a result, high levels of MA can be characterized as an avoidance reaction: individuals with high MA are fearful when performing math tasks and, consequently, they often avoid mathematically oriented university majors and career paths (Ashcraft \& Krause, 2007; Ashcraft \& Moore, 2009; Ashcraft \& Rudig, 2012).

An important factor to consider when looking at the relationship between MA and academic performance is the influence of gender and developmental changes. In terms of gender differences, some studies have reported the negative relationship between MA and math to be stronger in girls than in boys (Devine et al., 2012; Dowker et al., 2016; Else-Quest et al., 2010). In some studies, females have been reported to have higher levels of math anxiety than males on average (Hembree, 1990; Karimi \& Venkatesan, 2009), and this gender difference seems to increase with student age (Hill et al., 2016). However, the literature on this topic remains unclear; although several cross-sectional studies found no gender differences in MA levels (Ahmed, 2018; Birgin et al., 2010; Chiu \& Henry, 1990; Newstead, 1998), a meta-analysis showed that girls reported higher MA than boys despite negligible gender differences in math performance (Else-Quest et al., 2010). It is worth noting though that not all studies considered objective measures of mathematics performance (Ahmed, 2018). An attempt to clarify these inconsistent findings has been provided by the very recent metaanalysis of Barroso and colleagues, in which the authors found that the correlations for both gender were similar in strength and magnitude (Barroso et al., 2021). 
Looking at MA from a developmental perspective, the negative relationship between MA and math performance may increase across years of schooling (Dowker, 2005; Hembree, 1990; Hill et al., 2016; Wu et al., 2012). Recent results suggest that this negative relationship seems to emerge later in the educational timeline (Hill et al., 2016). Indeed, it is conceivable that MA could be more strongly associated with academic problems in secondary education (Morsanyi et al., 2014; Wu et al., 2012), when the math curriculum becomes more cognitively demanding. However, there is again variability in the published results. In some studies, MA has been reported in students attending second grade, which is one of the earlier primary school grades (Jameson, 2014; Ma \& Kishor, 1997; Ramirez et al., 2013; Vukovic, Kieffer, et al., 2013a). While most studies show increased anxiety with age, others found that children in second grade showed greater MA than children in later primary school grades (Sorvo et al., 2017). As Hembree's (1990) meta-analysis reported, MA correlates $(r=-.27)$ with math achievement scores in pre-college students, and $(r=-.31)$ in college students. Similarly, in their recent meta-analysis, Namkung et al. (2019) found this negative relationship getting stronger with age $(r=-.27$ for primary grades and $r=-.36$ for secondary grades). As the authors mentioned, the extent of this correlation could vary according to the specific questions included in the MA questionnaires, as well as according to the type of mathematical task involved. A less clear pattern emerged from Barroso's results (Barroso et al., 2021) as they coded studies based on grade levels rather than ages, without considering the inconsistency across countries and educational systems. Nonetheless, the authors found a significant relation between MA and math achievement across grades, since as early as grade 1 , but this relation does not follow a linear trend throughout development.

\section{Test Anxiety}

TA is characterized to be (a) context specific (e.g. evaluative situations in educational settings) and (b) found in a variety of academic subjects (Hembree, 1990), including English, science, mathematics, and social sciences (McDonald, 2001; Zeidner, 2007), and (c) is usually assessed without any connection to a specific academic domain but rather to general academic performance (e.g. Bandalos et al., 1995; Cassady \& Johnson, 2002; Elliot \& McGregor, 1999; Gierl \& Rogers, 1996). Two meta-analyses have reported a small but reliable effect between TA and academic performance, where a higher degree of self-reported anxiety is associated with a lower assessment performance in aggregated measures of academic achievement (Hembree, 1988; Seipp, 1991). Similarly, a recent meta-analysis by von der Embse et al. (2018) confirmed a consistent pattern of relationships where higher levels of test anxiety correlated with lower levels of academic performance across various testing formats (effect size range $-.13<r<-.40$ ).

To date, only a few studies have looked specifically into the relationship between TA and math performance. In his meta-analysis, Hembree (1988) highlighted a significant negative correlation between TA and mathematics performance from grade 4 to post-secondary levels $(r$ $=-.22$ ). Similarly, Putwain (2008) found a relationship between TA and math score $(r=-.21)$, when investigating the relationship between TA and a national standardized assessment taken at the end of secondary school in England, Wales, and Northern Ireland (the General Certificate of Secondary Education, GCSE).

The literature identifies gender and age as important sociodemographic moderating variables in the relationship between TA and performance (Hembree, 1988; Zeidner, 1990). 
Gender differences in TA were reported as a robust finding, with female students experiencing higher levels of test anxiety than male students ( $r=.21$; von der Embse et al., 2018). This disparity between genders occurs at all grade levels and is a gap that seems to increase during primary and secondary school years, and then slightly decrease in post-secondary education (von der Embse et al., 2018). Although several studies suggested that gender differences are predominantly (or solely) attributable to increased emotionality in females (e.g. Zeidner, 1990; Zeidner \& Schleyer, 1999), recent findings suggest that female students present with higher TA in the affective component of this type of anxiety (Putwain, 2008; Putwain \& Daly, 2014). Gender differences may be also influenced by ethnic background, as highlighted by Seipp's meta-analysis (1991). In this work, Seipp showed that gender seemed to moderate the relationship between anxiety and performance to a substantial degree in studies conducted in the USA, while in Germany and "other" countries, males and females seem to be equally inhibited by anxiety. These cultural differences fit well with the hypothesis that the origin of TA lies in the academic expectations that parents and teachers place on their children, with children fearing the consequences if they do not meet these expectations (Mueller \& Dweck, 1998; Sarason \& Sarason, 1990).

As for developmental changes, as children move through the educational system, they tend to be tested more frequently, both for pragmatic reasons (e.g. increasing subject number complexity) but also for more legislative reasons (e.g. the use of test-based accountability policies) (Duckworth et al., 2012). As testing became prominent, schools, teachers, parents, and students are under growing pressure to meet rising standards. Performance on a highstakes test may indeed determine important outcomes for students and parents (e.g. graduation and scholarships), for teachers (e.g. tenure and merit pay), and schools (e.g. funding, and annual performance goals). From a developmental perspective, studies have indeed suggested that more frequent testing may have led to the increased prevalence of TA over time (e.g. Hill \& Sarason, 1966; Putwain, 2007; Putwain, Woods, \& Symes, 2010b). It is notable, however, that none of these studies used a longitudinal design, which is normally required to assess change over time.

\section{Academic Anxiety and Working Memory}

\section{Math Anxiety}

Although the relationship between MA and math performance is well documented, the cognitive mechanisms underlining this relationship are not well understood. Some researchers argued that MA has a negative effect on math performance by impairing working memory (WM; Ashcraft \& Kirk, 2001; Mammarella et al., 2015; Ramirez et al., 2013). Working memory is a limited capacity system for the temporary maintenance and manipulation of stimuli (Baddeley, 1986), and several WM models have been proposed. The classical tripartite model (Baddeley \& Hitch, 1974) is the most common, and is distinguished by two slave systems (verbal and visuospatial), together with a central executive component. Alternative WM models have also been proposed but will not be discussed here (see Cornoldi and Giofrè (2014) for a review). It has been suggested that cognitive control is an important factor when considering WM capacity, with a distinction between tasks requiring a lower level of cognitive control (i.e. short-term memory (STM) or simple span tasks), which can be distinguished from tasks requiring higher levels of cognitive control (i.e. WM or complex span tasks) (Cowan, 2016; Engle \& Kane, 2004). 
It has been proposed that individuals with high MA suffer from intrusive thoughts of failure when attempting to solve mathematical problems, and that this occurs more often than in individuals with low levels of MA. This indicates that cognitive factors, such as attention control and WM, could play a central role in explaining the anxiety-performance link (Eysenck \& Calvo, 1992; Eysenck et al., 2007). It is suspected that these worrying thoughts (i.e. the cognitive component of MA) overtax individuals' WM systems, thus making it harder for them to solve math-related problems (Ashcraft \& Krause, 2007). Since most arithmetic processes such as simple counting and estimation, long division, problem-solving, and algebra rely heavily on the WM system (Ayres, 2001; Siegler \& Booth, 2005), Ashcraft and colleagues (Ashcraft \& Kirk, 2001; Ashcraft \& Krause, 2007; Ashcraft \& Rudig, 2012) argued that MA affects math performance by compromising cognitive processing. In support of this, Eysenck's processing efficiency theory provided a theoretical rational for exactly such an explanation (Eysenck \& Calvo, 1992). Another theoretical explanation for the negative impact of anxiety on performance is provided by the attentional control theory (Derakshan \& Eysenck, 2009; Eysenck et al., 2007). According to this theoretical approach, the key assumption that anxiety increases the allocation of attention to threat-related stimuli means that anxiety typically reduces attentional focus on the current task unless it involves threatening stimuli. In other words, anxiety affects the efficient functioning of the goal-directed attentional system by worsening the efficiency of executive functions, which are important to update and monitor the information currently within WM (Derakshan \& Eysenck, 2011).

\section{Test Anxiety}

Regarding TA, only few studies investigated the role of WM in the relationship between TA and arithmetic task performance in children (Korhonen et al., 2018; Ng \& Lee, 2010, 2015). Taken together, these studies support cognitive theories which attribute the anxiety-performance link to various cognitive factors, such as attention control and WM. Some studies examined the role of WM from an experimental (e.g. $\mathrm{Ng} \&$ Lee, 2010, 2015) or a differential perspective (i.e. individual differences in WM and executive functioning mediated the negative relation between trait anxiety and academic performance; Owens et al., 2012; Owens et al., 2008). However, Korhonen et al. (2018) suggested that both perspectives should be considered simultaneously to better understand the interplay between TA and WM on academic achievement.

It seems clear that the role of WM on the relationship between MA, TA, and math performance depends on a variety of factors. Some of these factors include the type of tasks being used to assess both math ability and WM, as well as the age and skill level of the participants (Raghubar et al., 2010). Adults with high MA and a high WM capacity may perform better than individuals with high MA but low WM capacity based on the Processing Efficiency Theory (Miller \& Bichsel, 2004). However, it has also been suggested that individuals with a high WM capacity could be more susceptible than individuals with a low WM capacity to a decline in math achievement when under pressure, due to what is colloquially referred to as "choking" (Beilock \& Carr, 2005).

\section{The Current Meta-analysis}

Given the potential impact of academic anxiety on math achievement, we decided to conduct a systematic meta-analytic review across the last 30 years of existing literature. Due to the recent publications of three meta-analyses separately targeting MA and TA (Barroso et al., 2021; 
Namkung et al., 2019; and von der Embse et al., 2018, respectively), in the present work, we wanted to specifically consider the impact of both MA and TA on math attainment. In addition, we also included the analyses of several other factors, at both the cognitive and the emotional level. Thus, this is the first attempt to take into account the relative contribution of different factors in a systematic, up-to-date, and comprehensive meta-analysis. This approach allowed us to address some of the limitations that emerged from the past literature. Specifically, we analyzed the effect of many potential variables that could moderate the relationship between MA, TA, and math performance, such as gender, age, type of mathematical task, and WM tasks. Moreover, we specifically targeted also the mediating role of WM, as a more general construct. A small number of published studies have considered MA and TA in the same analysis, while statistically controlling for general anxiety (Carey et al., 2017; Mammarella et al., 2018). From a statistical perspective, however, this is important, because if two factors are highly correlated but not controlled for, the effect of one variable might be fully accounted for by the shared variance between these factors. This regards also general anxiety, which is related with both MA and TA to some extent, thus potentially playing a role in the relationship between anxiety dimensions and math performance, as it shares some risk factors. It is worth noting that general anxiety has a moderate and consistent relationship with both MA and TA (but is less related to the former than to the latter; Hembree, 1990), and it might play a role in the relationship with math performance (Hill et al., 2016). This is consistent with the idea that the relationship between different forms of anxiety can be related to shared risk factors. Thus, TA and MA are likely to have more similar risk factors between each other (e.g. those with a root in school experiences and achievement) than general anxiety has with MA or with TA. In support of this, Carey et al. (2017) tested differences and developmental changes between anxiety forms (MA, TA, and general anxiety) in a large cohort of primary and secondary school students $(N \approx 1700$; grades 4,7 , and 8$)$; they found that the three forms of anxiety are less differentiated in primary school (i.e. they equally correlate with math performance) but become more differentiated in secondary school (i.e. separate into generally anxious vs academically anxious profiles). Mammarella et al. (2018) replicated and extended these results by testing children along a continuum, from grades 3 to 6 . They identified an intermediate stage of anxiety development, where general anxiety seems to act as a risk factor for the onset of other forms of academic anxiety (such as MA and TA).

No previous meta-analyses have assessed the specific role of both MA and TA on math performance, while also considering these different variables. In contrast with the metaanalysis of Namkung et al. (2019), but similarly to Barroso et al. (2021), we also included college age (adult) students, to understand the development of MA over time. We also considered gender differences and classified both math performance (i.e. arithmetic, basic numerical competences, grade scores, and math-applied performances) and WM tasks (i.e. verbal, visuospatial components, short-term and WM tasks) into four complexity levels. Furthermore, in contrast to von der Embse et al. (2018), who investigated the influence of TA on a range of educational outcomes, we only included studies that directly tested the specific relationship between TA and math performance. Lastly, we also extended the level of analysis by looking at the mediating role of WM to shed further light on its specific weight within the MA-math achievement relationship.

Overall, the main objectives of the present meta-analysis were (i) estimating the impact of MA and TA on math performance; (ii) measuring the impact of potential moderators on the MA/TA and math relationship, by taking into account gender, age, type of math tasks, and type of WM tasks; and (iii) assessing the mediating role of WM when considering MA and math achievement relationship. 


\section{Method}

\section{Literature Search and Inclusion Criteria}

Primary research papers, in English, with quantitative data were reviewed. Only papers published from 1990 to 2018, in peer-reviewed journals, were included. Papers reviewed varied in their methodologies and studies were included if they directly measured math achievement or performance, WM, MA, and TA in typical developing individuals. The preferred reporting items for systematic reviews and meta-analyses (PRISMA) 2009 checklist were followed when writing this review. When assessing the risk of bias, the protocol described by Sirriyeh et al. (2012) was used.

We conducted an electronic survey of five online databases: Web of Science, Scopus, PubMed, Medline via Ovid (1996-present), and PsycINFO via Ovid (1996-present). When possible, a full text search was conducted, and in cases in which the full text search was not available, a search of the keyword (PsycINFO) or topic (Web of science) was conducted. The search terms used included "math* anxiety", "test anxiety", "performance", "achievement", and "working memory". The wildcard * was used where variations like "math"/"maths"/ "mathematics"/"mathematic"/"mathematical" might occur. Math* AND Anxiety AND (Achievement OR performance OR "working memory"). All search terms were combined in the same way on all databases, but some databases had different ways of inputting this. In order to include grey literature, we performed the same survey (using exactly the same procedure, same years, search terms, and Boolean operators) on ProQuest platform. We focused in particular on dissertations, theses, and conference proceedings.

After conducting systematic searches in each of the five databases, 3,223 articles were collected in total. Data were exported from each database into an EndNote library, and 1,360 duplicates were removed, leaving a total of 1,863 records. The remaining papers were exported into a Microsoft Excel spreadsheet. Two independent reviewers (S.C. and J.M.R.) independently evaluated each article and decided whether each specific paper was to be included in the meta-analysis. Disagreements were resolved by a third reviewer (I.C.M). As for the grey literature, the research was conducted through three different libraries (University of Padova, Genoa, and Leeds) resulting in 141 retrieved documents. After duplicate removal, a total of 109 abstract were screened by the two independent reviewers. To improve our strategy search, we also emailed leading researchers in the field requesting unpublished data, dissertations, as well as articles published on non-peer-reviewed journals that could be fit with the aims of the present meta-analysis.

Studies were entitled to be included in the meta-analysis if they met the following inclusion criteria. In the full-text analyses, we focused on three different study designs: (a) correlational studies, (b) longitudinal prediction studies, and (c) experimental studies. To prevent violating the independence of observations in longitudinal studies, data only from the first time point were coded. Similarly, for experimental or intervention studies, only data from control groups or pretest period were coded. As for studies following an extreme-groups design (e.g. high vs low), only data from the initial screening were included, when available. Moreover, we only included studies reporting original empirical findings (i.e. not a review or re-analysis of findings that were reported previously). The inclusion of each study and its effect sizes in the database was based on the inclusion of at least one mathematical performance measure and one math/test anxiety assessment. Studies assessing perceived math competence or individuals' self-reported beliefs about their math skills were excluded. Thus, studies had to either report zero-order correlation coefficients or report data made the calculation of correlation coefficients possible. When these were not reported, effect sizes were requested from authors via e-mail. 
In a second phase, title and abstract screening were conducted and reviewers excluded 1,342 records that did not measure MA/TA or math performance, leaving 521 articles to be assessed for eligibility through full-text exploration. Similarly, for the grey literature, out of the 109 documents, only 65 were eligible for full-text screening. These documents were then subject to close review using the above outlined inclusion/exclusion criteria. Based on the fulltext analyses, 370 peer-reviewed studies were removed, leaving a total of 151 studies. To these are added 26 documents from the full-text screening of the grey literature, reaching a total of 177 studies included in the present meta-analysis. Details concerning the literature search, inclusion criteria, and selected studies are shown in the flow chart below (Fig. 1).

\section{Coding of the Studies}

Extracted data included details on the study such as title, authors, year and type of publication, and author contact details. Details about the sample were also included such as sample size, mean age, and gender. It must be noted that each study could include more than one sample of participants (e.g. groups of children in different grades, or males and females separately), which we treated as

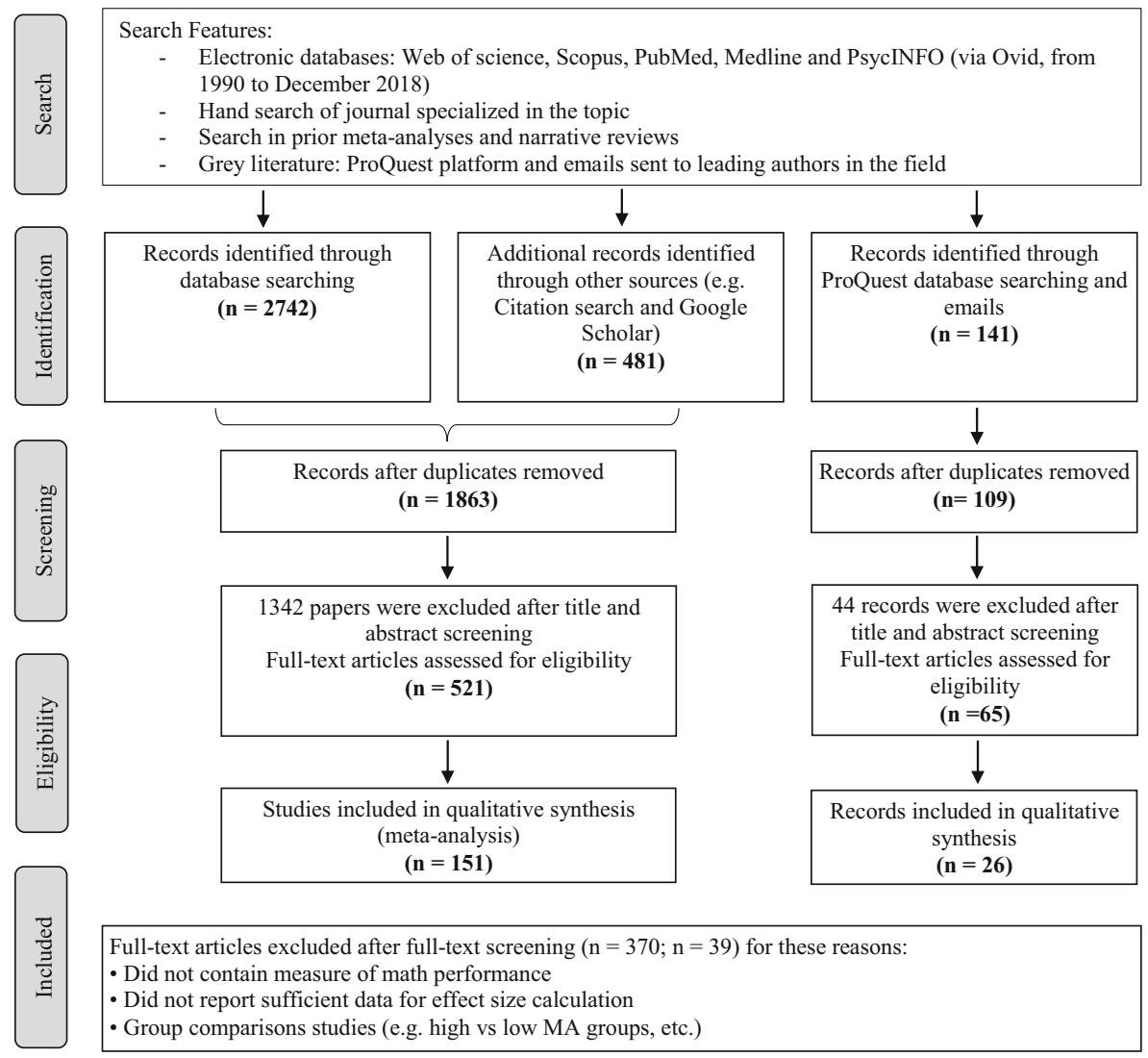

Fig. 1 Flow diagram for the search and inclusion criteria for studies in this meta-analysis. Adapted from "Preferred Reporting Items for Systematic Reviews and Meta-Analyses: The PRISMA Statement," by D. Moher, A. Liberati, J. Tetzlaff, D. G. Altman, and The PRISMA Group, 2009, PLoS Med 6(6). Copyright 2009 by the Public Library of Science 
independent samples (further details are given below in the "Meta-Analytic Model Fitting" section). Concerning the effect size, all correlations of interest (i.e. those involving MA, TA, GA, math achievement, and WM) were coded, along with the combination of constructs that they involved (e.g. "MA-Maths", "MA-WM"). As the same study could report more than one correlation for the same combination or sample (or for different combinations or samples), the dataset included as many rows per study as were the effect sizes of interest that it reported. When outcomes involved response times or error counts, the signs of the effect size were inverted.

To investigate the moderators of interest, we coded (1) where effect sizes were reported separately for boys and girls, and (2) age group classifications (i.e. child or adult). For math performance, we coded math measures as tapping (a) school grades, (b) basic numerical knowledge, (c) arithmetical skills only, or (d) more advanced and complex skills. Where WM measures were available, we also coded the type of task as WM or STM, and the type of material as verbal or spatial.

Additional details on test characteristics were coded for each of the three main domains considered (i.e. emotional factors, achievement, and cognitive factors). Specifically, for each measure, we summarized test content (i.e. the skills measured by the test), complexity (i.e. for mathematical skills, low complexity would be basic math knowledge while more advanced arithmetic abilities would be classified as applied math), origin (i.e. standardized battery, national survey, or experimental task), and reliability of the measure(s) where available.

\section{Analytic Strategy}

\section{Risk of Bias Across Studies}

The presence of possible publication biases in the meta-analysis was tested and quantified using the "trim-and-fill" method (Duval, 2005). This method estimates the number of studies missing because of the publication bias (i.e. due to the fact that studies reporting nonsignificant effects are less likely to be published).

Unlike other methods aimed at assessing the publication bias, the trim-and-fill method aims at directly quantifying the potential bias (Borenstein et al., 2009). This method provides an estimate of the adjusted effect when the hypothesized missing studies are included. This estimate should not necessarily be regarded as a more valid than the non-adjusted effect, however. Rather, it can be interpreted as a publication bias-adjusted estimate under the assumption that the asymmetry observed in the distribution of the effects is due to publication bias (as explained by Borenstein et al., 2009, p. 291). However, other reasons of publication bias may exist, e.g. studies with smaller samples may have performed better quality control on data collection than larger studies. In the current study, we decided to use a one-side hypothesis testing as suggested by Borenstein et al. (2009), and due to the fact that the trimand-fill correction was used to control for possible publication biases. This approach was used to deflate, never to inflate, the magnitude of the effect sizes.

\section{Meta-Analytic Model Fitting}

The analytic strategy adopted in this meta-analysis followed the guidelines proposed by Borenstein et al. (2009), as well as Schwarzer et al. (2015). R was used in all the analyses ( $\mathrm{R}$ Core Team, 2019) and meta-analyses were performed using the random effects models function implemented in the "metafor" (Viechtbauer, 2010) package. We decided to use 
random effects models because this analytic strategy allows us to better account for the heterogeneity among studies (i.e. it avoids overestimating the precision of the final metaanalytic values). This analytic approach assumes that different studies can be sampled from a normally distributed population of underlying effect sizes, rather than reflecting an identical effect (Borenstein et al., 2009).

Correlational values were reported as Pearson's $r$ in the majority of cases (94\%), or by Spearman's rho (4\%) and model beta coefficients $(2 \%$; when needed, that is when they were reported as raw estimates, we standardized the beta coefficients by using the reported SDs of the covarying variables). All estimates were transformed into the Fisher's $Z$ scale before computing the meta-analysis (see Borenstein et al. (2009) for more details).

All eligible effect sizes were considered, and when multiple effects were reported for the same outcome combination in the same sample of individuals (e.g. a certain construct was measured by means of different indicators on the same group of participants), effects were combined using the formulas for non-independent outcomes reported by Borenstein et al. (2009, pp. 227-228). To compute the combined variance for an effect, a conservative estimation of the between-effect correlation was made with $r=.80$. Sensitivity analysis showed that the results were robust, as the effect sizes varied by no more than .01 for any $r$ between .50 and .95 . Studies that reported data on a single overall sample were $75 \%$, whereas $25 \%$ of studies included effects on multiple samples. Independent samples included in the same study were considered as independent information and were thus included separately in the meta-analyses (Borenstein et al., 2009, p. 218).

\section{Heterogeneity and Test of Robustness}

Heterogeneity across independent samples was quantified using $\tau^{2}$, which is a measure of estimated variance, and by using the $R^{2}$ index, which can be interpreted as the percentage of total variance of the estimated effect that is attributable to the variance across studies (Higgins et al., 2003). Lower values of $P^{2}$ (i.e. $P^{2}<50 \%$ ) suggest limited heterogeneity across studies, indicating that the estimated effect sizes are generalizable. Higher values of $P^{2}$ (i.e. $R^{2}>75 \%$ ) suggest that there are large differences across studies (e.g. investigation of different constructs, or sampling from populations in which the true effects are very different; see Higgins et al. (2003) for more details).

To test the robustness of the results, all meta-analyses that included at least three independent effects (which implies at least three independent samples, as effects were aggregated by sample) were tested using the "leave-one-out" method (Viechtbauer, 2010). This method computes a series of meta-analyses excluding one single effect at a time. The range of variation of the estimated meta-analytic effect was then reported for each meta-analysis.

\section{Analysis of Moderators}

Moderating analyses were conducted using multilevel models, with each sample entered as a random effect. Multilevel modelling seemed the best choice in this case, as most studies reported effects simultaneously on different levels of the same moderating factor. For example, concerning the type of WM task, several samples of participants were tested both on verbal and on spatial tasks, meaning that the studies investigated correlated effects across different levels of the same moderating factor. Thus, multilevel modelling was the best way to account for the structure of dependencies among the effects. For consistency with the analyses 
described above, we combined the effects by independent sample using the formula suggested by Borenstein et al. (2009, pp. 227-228), but did so separately for each level of the moderators of interest. For gender, study was entered as a random effect instead of individual samples, because males and females are naturally grouped as different samples.

Estimated coefficients were obtained using the "restricted maximum likelihood" method, which is set by default in the "metafor" package. Nonetheless, model comparisons, conducted by mean of likelihood ratio tests for nested models, were conducted on models fitted using "maximum likelihood". This is due to the fact that models are not comparable when fitted with the "restricted" method; all of these specifications are set by default by the "metafor" package.

It should be noted that significant and non-significant effects of moderating factors were the same, even without multilevel models and without random effects of samples (or studies), even though the coefficient slightly changed when random effects are not included. This suggests that the moderating analyses were robust, with only minor variations in the estimated coefficients, which occur independently of the specific analytical choices.

\section{Mediation Analysis}

An additional analysis of mediation was conducted to examine the role of WM as a mediator between MA and math achievement, and between TA and math achievement. To do so, multivariate regression models (or "meta-path analysis", as shown in Fig. 3) were used. The models were fitted - and their direct and indirect effects were estimated — using the "lavaan" (Rosseel, 2012) package in R.

We conducted this analysis using two different alternative strategies. First, we sought to take into account the random effects of samples on direct and indirect effects of interest. Therefore, we restricted this analysis to studies that reported complete correlation matrices for anxiety, WM, and math achievement. For each of these "complete" studies, we fitted a separate mediation model. Subsequently, we meta-analyzed all direct and indirect effects of interest using random effects models.

For the second strategy, we incorporated the maximum information available, at the cost of no longer considering random effects (see Yu et al. (2016) for a discussion of the problems with not considering effect size heterogeneity in meta-analytic structural equation modelling). To do this, we computed the mediation model from a correlation matrix (including anxiety, WM, and math achievement), which was composed using the meta-analytic correlations independently estimated by different meta-analyses, each of which included as many studies as possible. We performed this analysis to obtain additional estimates of the direct and indirect effects, for possible convergent evidence with estimates from the first strategy. To quantify uncertainty in model estimates, we adopted a Monte Carlo simulation approach based on the meta-analyzed correlations among MA (or TA), WM, and math achievement. As the present meta-analysis was not focused on the relationship between WM and math achievement, this specific correlation (and its standard error) was taken from the meta-analysis by Peng et al. (2016), while the other correlations were taken from the present meta-analytic study (Table 1). At every 10,000 iterations in our Monte Carlo simulation, we sampled all three correlations of interest (sampling distributions were normal distributions with the mean corresponding to the estimated meta-analyzed correlations in Fisher's $z$, and SD corresponding to their standard errors), and we fitted a mediation model using "lavaan" (see Fig. 3) to estimate all direct and indirect effects of interest. As final estimates, we reported the median values of the distributions, together with the $95 \% \mathrm{CI}$ as the range of values between the 2.5 and the 97.5 percentiles, as a measure of uncertainty. 


\section{Results}

\section{Overview}

A total of 177 studies and 250 distinct independent samples (for a total of 906,311 participants) were included in the analyses presented below. Table 1 summarizes all meta-analyzed effects, including parameter estimates computed according to the analytic strategies. Forest plots for the main meta-analyses are reported in the Supplementary Material (Figures S1-S8), and funnel plots are reported in Fig. 2.

Moderation analyses were conducted for all combinations of outcomes, for which we examined subsamples of effects, as summarized in Table 2. Wherever possible, we examined the results separately by gender, age group (children and adults), type of math task (arithmetic, basic knowledge, grade, and applied math), WM type of material (verbal and spatial), and WM type of task (simple short-term memory and active WM tasks). All these variables were tested as possible mediators in the meta-analyses. Due to the limited number of possible combinations across levels of different moderators, we chose not to investigate possible interactions.

\section{Math Anxiety and Math Achievement}

The overall correlation between math anxiety and math performance, calculated on 169 independent samples within 121 different studies, was $r=-.30[-.32,-.28 ; p<.001]$. The heterogeneity across the samples was high, $I^{2}=98 \%$, with a $\tau=0.15$, suggesting the existence of important moderating variables. This extreme estimate for heterogeneity can be explained by the fact that two of the samples involved had more than 250,000 participants each, thus leading to virtually null sampling errors for at least two of the effects. The trim-and-fill method did not indicate any asymmetry distribution and did not correct for possible publication bias.

Table 2 shows that math type is a significant moderator of the relationship between math performance and math anxiety. Regarding the type of math task, 78 studies assessed applied math (i.e. more advanced math complex skills), 43 studies assessed arithmetic, 38 assessed math grade, and just 10 studies assessed basic knowledge. The latter showed the smallest relationship with math anxiety, $r=-.22[-.34,-.09 ; p<.001]$, while all other correlations with math anxiety were moderate and ranged from $-.25[-.28,-.22 ; p<.001]$ to $-.31[-.34,-.28 ; p<.001]$.

As shown in Table 2, gender was not found to be a significant moderator of the relationship between math performance and math anxiety, as the relationship between math performance and math anxiety was only slightly stronger in females than in males, $B=.09, p=.075$. This data should be interpreted with caution, however, as only a relatively small number of studies provided information divided by gender (16 studies in total, giving an overall 21 independent samples of males, and 21 for females).

Finally, age group emerged as a significant moderator of the relationship between math performance and math anxiety (Table 2 ). The estimated relationship differs to a very limited extent between children, $r=-.31[-.33,-.28 ; p<.001]$, and adults, $r=-.25[-.29,-.21 ; p$ $<.001]$, but it should be noted that the latter estimate further dropped to $-.22[-.26,-.19 ; p<$ $.001]$ after trim-and-fill adjustment.

\section{Math Anxiety and Working Memory}

WM measures were coded according the type of content and degree of cognitive control involved. Regarding the former, most studies used verbal working memory tasks (20 studies totaling 21 independent 


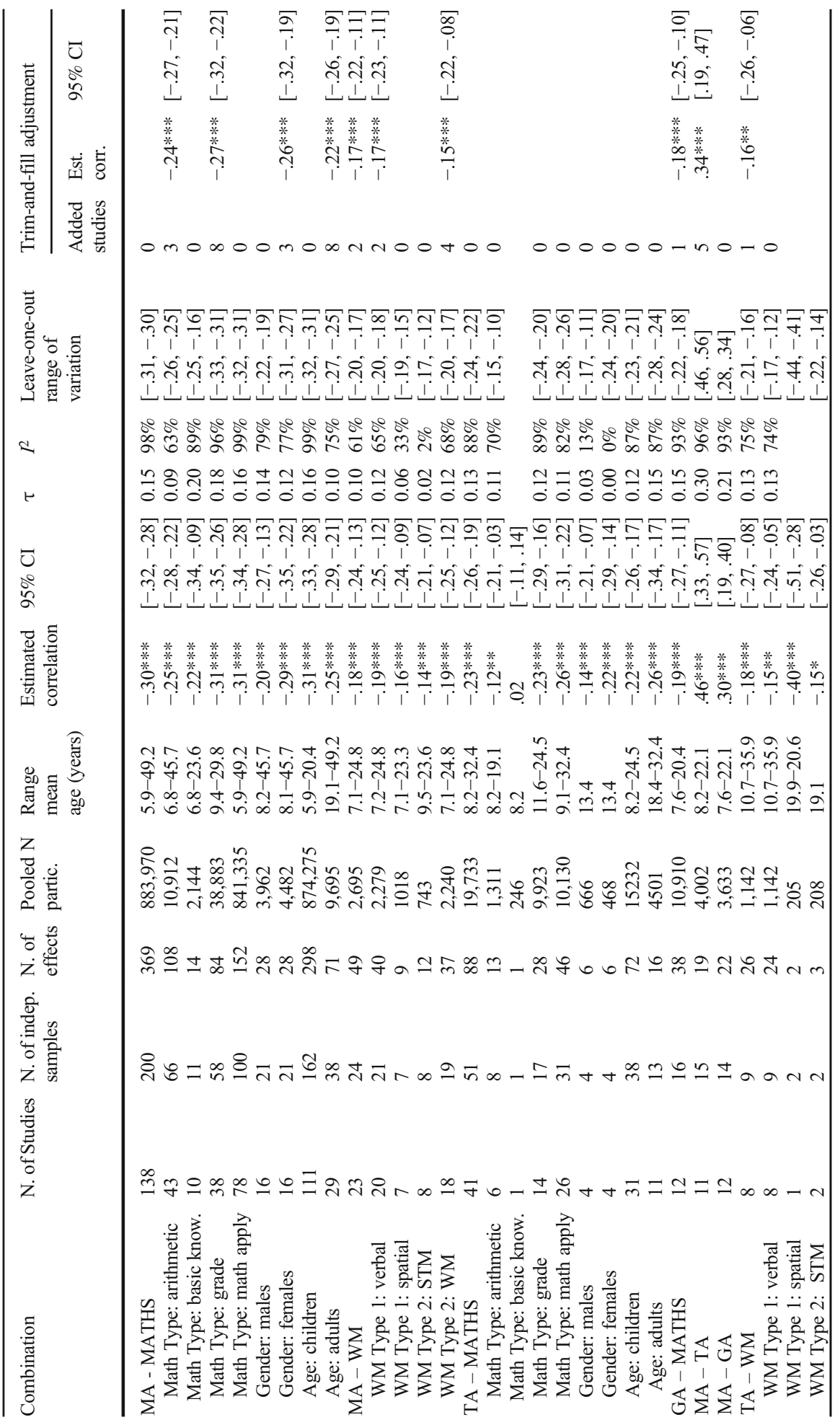




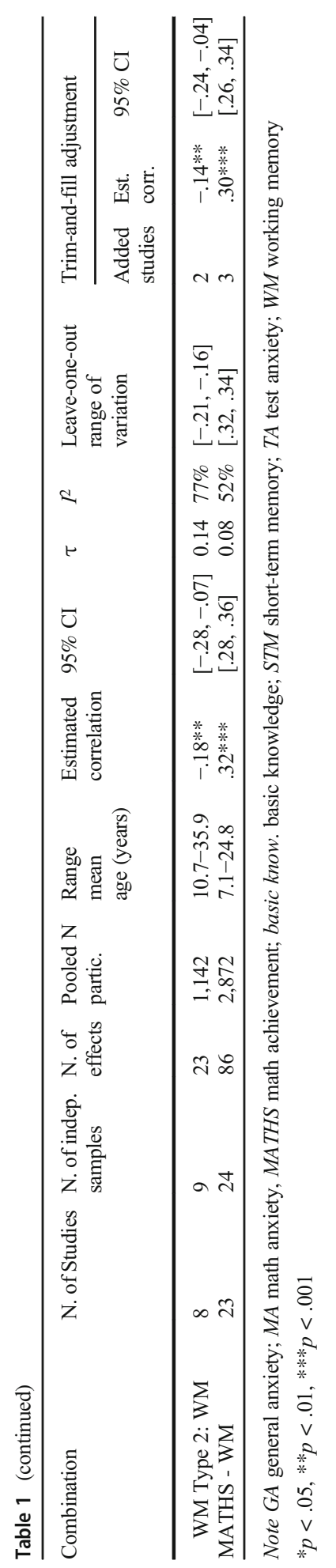


(A) Math Anxiety-Math Achievement

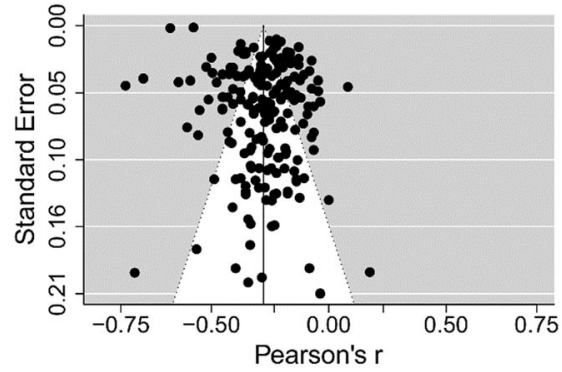

(C) Test Anxiety-Math Achievement

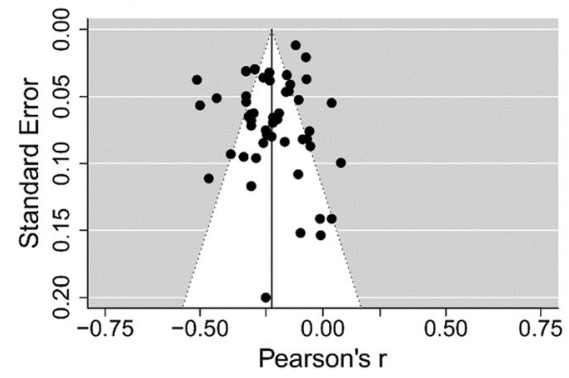

(E) Math Anxiety-Test Anxiety

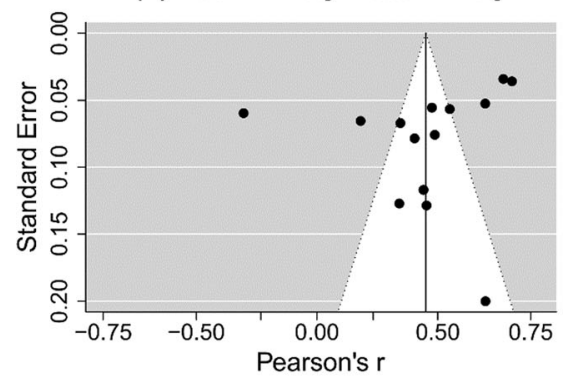

(G) Test Anxiety-Working Memory

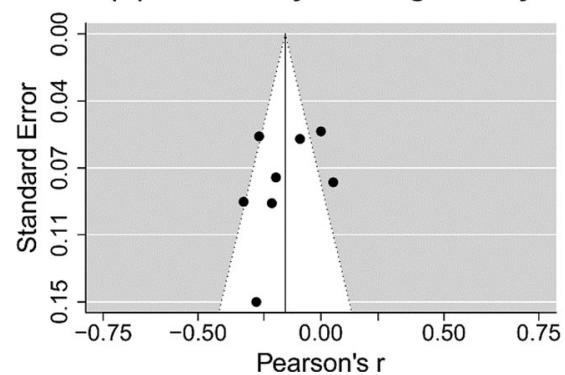

(B) Math Anxiety-Working Memory

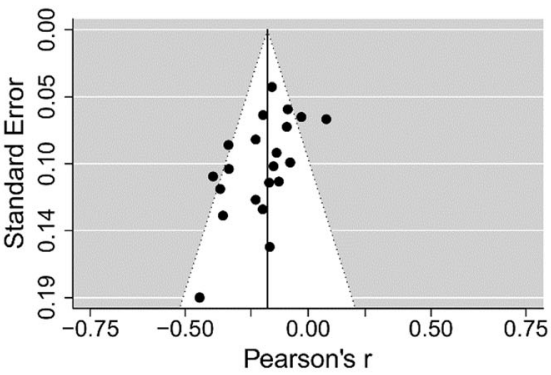

(D) General Anxiety-Math Achievement

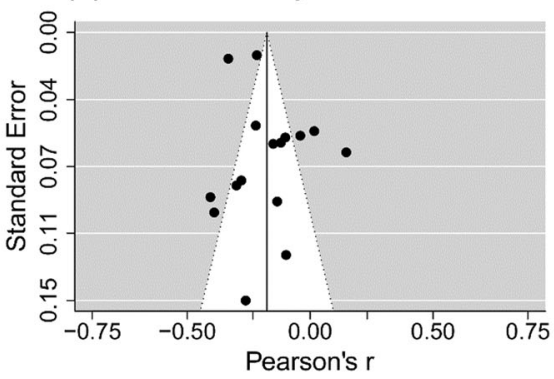

(F) Math Anxiety-General Anxiety

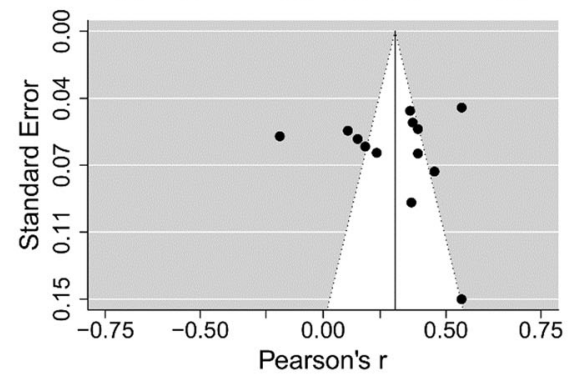

(H) Working Memory-Math Achievement

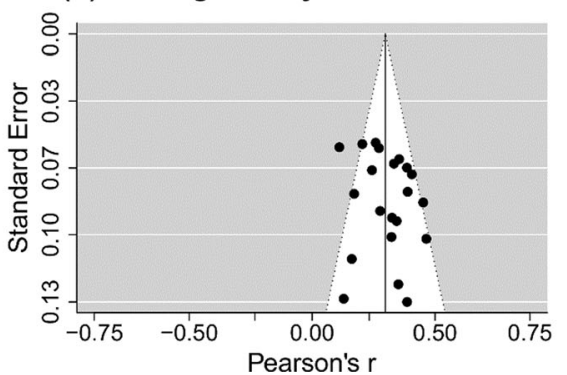

Fig. 2 Funnel plots for the main meta-analyses summarized in 8 panels $(\mathbf{A}-\mathbf{H})$

samples) rather than spatial working memory tasks (7 studies totaling 7 independent samples). However, type of material had virtually no impact on the correlation of interest (Table 2). The correlation between verbal working memory and math anxiety was $r=-.19[-.25,-.12 ; p<.001]$, while the correlation between spatial working memory and math anxiety was $r=-.16[-.24,-.09 ; p<.001]$. 
Table 2 Summary of the moderation analyses

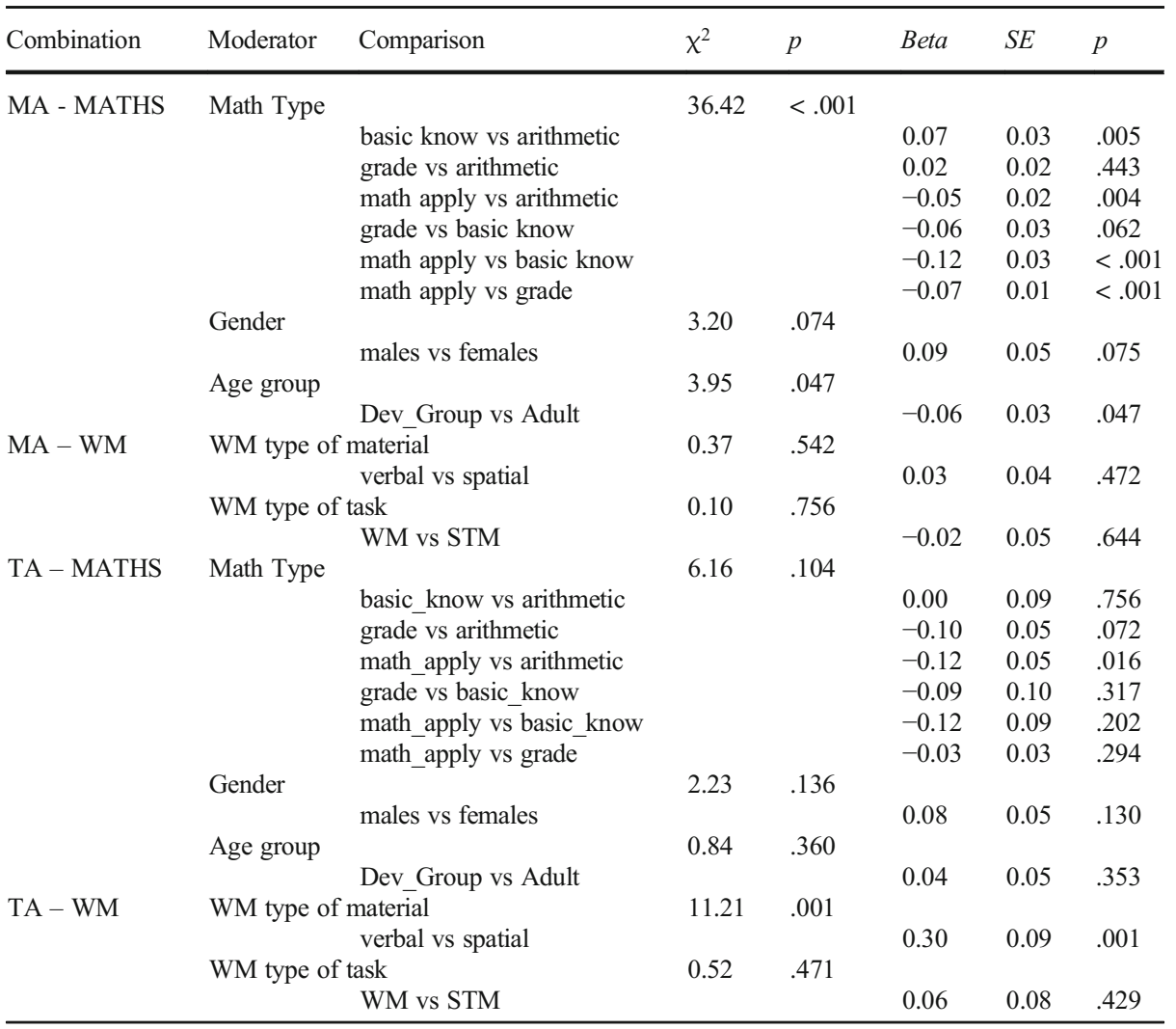

Note GA general anxiety, MA math anxiety, MATHS math achievement, STM short-term memory, TA test anxiety, $W M$ working memory

Similarly, involvement of cognitive control (short-term memory vs working memory) did not have a significant effect either on the relationships of interest (Table 2), albeit from a qualitative point of view, the connection appeared slightly weaker for short-term memory, $r=$ $-.14[-.21,-.07 ; p<.001]$, than for working memory, $r=-.19[-.25,-.12 ; p<.001]$, although the latter dropped to $r=-.15[-.22,-.08 ; p<.001]$, after trim-and-fill adjustment. Importantly, short-term memory was used in only 8 independent samples within our metaanalysis; therefore, the estimate is associated with a high level of uncertainty.

Finally, a negative relationship emerged between MA and overall WM measures, although this link was relatively weak, $r=-.18[-.24,-.13 ; p<.001]$. Level of heterogeneity was medium, $R^{2}=61 \%$, with $\tau=0.10$, suggesting that there might be moderating factors.

\section{Test Anxiety and Math Achievement}

The overall correlation between test anxiety and math achievement was notably weaker than the correlation between math anxiety and math achievement, $r=-.23[-.26,-.19 ; p<.001]$. The level of heterogeneity was high $\left(I^{2}=88 \%\right)$, with $\tau=0.13$, pointing to potential moderating factors behind the relationship between text anxiety and math achievement. Nonetheless, 
moderation analysis (Table 2) failed to show that any of the moderators considered (i.e. math type, gender, or age group) emerged as significant. With regard to gender, its potential moderating role pointed in the same direction as that found for the relationship between MA and math achievement (i.e. a stronger correlation in females than in males, $B=.08[-.02, .19 ; p$ $=.13]$ ). Once again, however, gender did not reach statistical significance as a moderator, likely due to the limited amount of available evidence (only 4 studies reported data on this).

\section{Test Anxiety and Working Memory}

The overall correlation between test anxiety and working memory was $r=-.18[-.27,-.08$; $p<.001]$, i.e. a weak correlation. Nonetheless, caution must be used when interpreting this data as only 8 studies were able to be included, for a total of 9 independent samples. Moderation analysis suggested that material type may also play a role, with a much stronger correlation for spatial than for verbal material, $B=.30, p=.001$. Again, caution should be used when interpreting this difference, as evidence for spatial working memory material was available in just one study.

\section{The Mediating Role of Working Memory between Anxiety and Math Achievement}

As explained above in the "Analytic Strategy" section, we examined the mediating role of WM using two alternative strategies. With the first, which was limited to studies reporting all variables of interest, we considered random effects. With the second, which was based on a Monte Carlo simulation approach, we sought to incorporate as much information as possible.

For the first strategy, our meta-analytic dataset had 15 independent samples reporting complete information for the mediation MA $\rightarrow \mathrm{WM} \rightarrow$ Math, and 6 independent samples reporting complete information for the mediation TA $\rightarrow \mathrm{WM} \rightarrow$ Math. The meta-analytic estimates, together with their 95\% CIs, are reported in Fig. 3, panel A. The main interest concerned the mediating role of WM, i.e. the indirect effect of MA on math achievement via WM. As can be seen, these indirect effects were all non-significant and negligible in terms of magnitude ( $B \leq .05$ for all samples) for both MA and TA.

Regarding the second strategy, the estimates are reported in Fig. 3, panel B. As can be seen, the final estimates for indirect effects can now be considered significant (as their CIs clearly exclude zero, which was expected as all original meta-analytic correlations were statistically significant; Table 1). However, these final estimates remain negligible in terms of their magnitude.

\section{Additional Analysis}

As reported above, the relationship between MA and math achievement appeared stronger than the relationship between TA and math achievement, even though both correlations were of medium strength. To formally test whether one correlation was stronger than the other, we conducted an additional meta-regression in which the correlations (involving MA or TA on one side, and math achievement on the other side) were examined in the same model. As in all previous cases, the correlations were combined by independent sample using the formula suggested by Borenstein et al. (2009), and the moderating analysis was conducted using multilevel models. Type of anxiety (math anxiety vs test anxiety) was then tested as the moderator of the relationship between anxiety and math achievement. The moderating role of 
A) Via meta-analytic multivariate regression

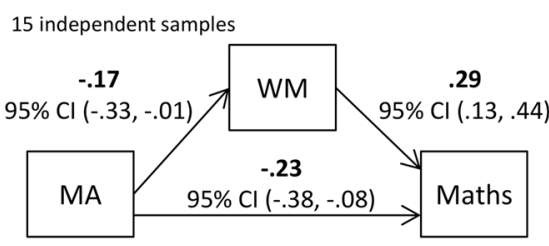

indirect effect MA $\rightarrow$ Maths: $\mathrm{B}=-.04,95 \% \mathrm{Cl}(-.12, .05)$

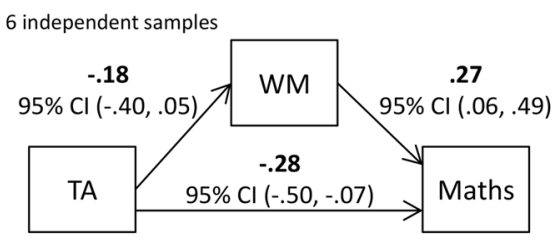

indirect effect $\mathrm{TA} \rightarrow$ Maths: $\mathrm{B}=-.04,95 \% \mathrm{Cl}(-.16, .09)$

\section{B) Via Monte Carlo simulation of multivariate regression}
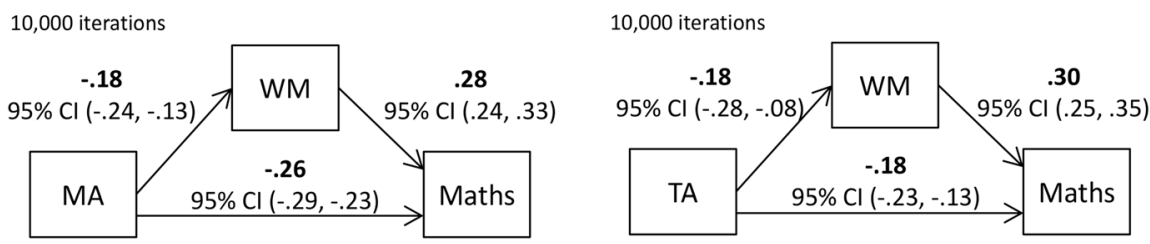

indirect effect MA $\rightarrow$ Maths: $B=-.05,95 \% \mathrm{Cl}(-.07,-.04)$ indirect effect TA $\rightarrow$ Maths: $\mathrm{B}=-.05,95 \% \mathrm{Cl}(-.08,-.03)$

Fig. 3 Mediation analysis on the relationship between math anxiety (MA), working memory (WM), and mathematical achievement (Maths), and on the relationship between test anxiety (TA), WM, and Maths. Panel (A) shows the estimates obtained via meta-analytic multivariate regression based on samples with complete correlations. Panel (B) shows the estimates obtained via Monte Carlo simulation of multivariate regression based on meta-analyzed correlations. All estimates are standardized regression coefficients

the type of anxiety was significant, $\chi^{2}(1)=14.09, p<.001$, and indicated that math anxiety has a stronger correlation with math achievement than test anxiety has with math achievement, although the difference was very small in terms of magnitude, $B=.07[.03, .10 ; p<.001]$.

\section{Discussion}

The present meta-analysis examined the relationship between different forms of academic anxiety (MA and TA) and math performance, taking into account the impact of potential moderators, such as gender, age, and type of math and WM tasks.

We confirmed a moderate, negative relationship between MA and math performance $(r=-$ .30). This is in line with previous meta-analytic studies in which the correlation between MA and mathematic achievement ranged from $-.27<r<-.34$ (Hembree, 1990; Ma, 1999; Namkung et al., 2019). We also found that this link was significantly affected by the nature of the math tasks as well as by gender. In contrast, age did not moderate MA. Similarly to Namkung et al. (2019), we found that advanced math domains requiring multistep processes showed a stronger negative correlation with MA (-.31) compared to foundational mathematics domains, such as early numeracy, which do not require multistep processes (-.22). In line with the recent meta-analysis of Barroso and co-authors, our meta-analysis confirmed that there is no difference between girls and boys MA experience (Barroso et al., 2021). It is worth noting that all the included studies reported an objective measure of math performance, thus overcoming the limitation recently raised by Ahmed (2018) when attempting to explain the heterogeneity of the results reported in previous studies. Contrary to Namkung et al. (2019), 
our results showed a significant (albeit weak) negative correlation between WM and MA, regardless of the type of material or the degree of cognitive control involved in the WM tasks.

In line with the previous literature (Devine et al., 2012; Hembree, 1988; Mammarella et al., 2015; Putwain, 2008), we measured a modest correlation $(r=-.23)$ between TA and math performance. The pattern of relationship between TA and math performance in different types of math task was the same as previously observed for MA, and perhaps even more accentuated. Nonetheless, type of math task failed to emerge as a significant moderator of the relationship between TA and math performance, likely due to the much smaller number of studies included in this analysis and the high heterogeneity. No demographic differences emerged according to gender and age, although higher correlations were found for girls and older students.

These results highlight how MA and TA share some risk factors (e.g. they both displayed effects trending in the same direction and were both negatively associated with academic success). At the same time, the results showed some specificity, as confidence intervals showed no overlap whatsoever, allowing us to make inferences about the stronger effect of MA on math performance. Similarly, Donolato et al. (2020) found that MA explained a larger portion of the unique variance in mathematics performance compared to TA, through a variance decomposition analysis. In other words, although MA and TA overlap to some extent, MA is more strongly associated with mathematics performance. Thus, it may be that GA (i.e. being generally anxious) and TA (i.e. being more specifically worried about academic performance and academic difficulties) are risk factors that may contribute to the development of a more specific form of anxiety-MA - and therefore be indirectly related to mathematical performance (Carey et al., 2017; Mammarella et al., 2018).

\section{Academic Anxiety and Math Performance: Type of Math Tasks and Demographic Variables}

In contrast to TA, where the impact of this type of anxiety has been investigated mainly in relation to general academic examinations (see Putwin 2008), a large body of research has demonstrated that MA negatively impacts math performance specifically. For example, individuals with high MA perform worse than their less math-anxious peers on basic numerical abilities, such as counting and comparing numbers (Maloney et al., 2010; Maloney et al., 2011), and perform worse on more advanced arithmetic problems, including complex mental calculations (Ashcraft \& Faust, 1994). A small number of studies have focused on this relationship while paying attention to specific aspects of math, confirming that the strength of the math-MA relationship tends to differ as a function of the complexity of math tasks (Ching, 2017; Vukovic et al., 2013a, b). MA seems to be more related to school mathematics performance (i.e. math tests, grades and/or specific contents, such as calculation skills and their mathematical applications), than using numbers in everyday contexts (Evans, 2000). Following this rationale and extending the dichotomous classification proposed by Namkung et al. (2019), we confirmed the effects of varying levels of math tasks on both forms of anxiety, in agreement with previous studies. However, future research is needed to further explore the domain specificity in the relationship between MA and mathematics performance.

The effect of demographic variables, such as gender and age, have been more extensively considered as important source of variance in both forms of academic anxiety. In general, girls consistently reported significantly more anxiety than boys in terms of both MA (Ferguson et al., 2015; Hembree, 1990; Maloney et al., 2012) and TA (e.g. Putwain, 2007; Putwain \& 
Daly, 2014; Zeidner \& Schleyer, 1999). This finding remains stable even when controlling for other kinds of anxiety, such as trait or state anxiety (Devine et al., 2012; Zeidner, 2014). In terms of gender differences, a few explanations have been proposed. Considering both forms of anxiety, it is plausible to hypothesize that a greater level of anxiety in girls may relate to several factors, including a lower level of self-perception and lower confidence (Cvencek et al., 2014; Fredricks \& Eccles, 2002; Marsh \& Yeung, 1998; Pajares, 2005), the fact that boys are less likely to openly state their negative feelings (Ashcraft \& Ridley, 2005), the fact that boys' answers are more affected by a recall bias as well as social desirability biases (Dowker et al., 2016), as well as the presence of gender stereotypes about math (Appel et al., 2011; Flore \& Wicherts, 2015). Although the average levels of anxiety may differ in girls vs boys, however, this does not imply that the relationship between anxiety and math performance should vary by gender. In fact, our results did not show that the relationship between either MA or TA and math performance was significantly moderated by gender, although the estimates was slightly larger for females than for males.

Further research is needed in order to clarify why female students frequently report higher level of anxiety compared to their male counterparts. Moreover, it is worth noting that in the present meta-analysis, we had a limited number of reviewed studies $(k=4)$ on the relationship between TA and math performance stratified for gender. The lack of studies could have influenced our results; thus, further studies are needed to investigate this relationship. In terms of MA, only 16 studies provided information divided by gender, out of the 138 studies included in the current analysis. Thus, given that previous studies have emphasized the importance of gender differences on both MA and TA, future studies should consider inserting gender information more explicitly.

In general, it can be stated that almost all students are challenged with some form of academic anxiety during their school years, and age may affect the experience and expression of this anxiety (Mammarella et al., 2019; Nyroos et al., 2015; Wren \& Benson, 2004). According to previous research, younger children face more physical symptoms (i.e. stomach pain or pounding heart) rather than cognitive (i.e. worry) symptoms compared to older students, while these older students more frequently experience intrusive thoughts (Whitaker Sena et al., 2007). When looking specifically at MA, most of the research has been carried out on secondary school children and adults. Studies including younger children typically indicate that primary school children tend to have more positive attitudes to math, and anxiety is mainly related to self-rating. These studies also mention that these attitudes tend to deteriorate with time and development (Hill et al., 2016; Krinzinger et al., 2009; Ma \& Kishor, 1997).

The influence of age on TA is less consistent across studies. Hembree's (1988) metaanalysis reported that TA increased during early elementary school grades and remained constant throughout high school. Alternatively, von der Embse et al. (2018) showed that middle school graders (i.e. ages 11-14) exhibited a larger negative relationship between TA and performance compared to high school students. Nonetheless, it is essential to consider the effect of age when examining students' academic anxiety (Zeidner, 2007). Our meta-analysis indicates that the relationship between MA and math performance is significantly stronger in children than in adults, although to a very limited extent (-.31 vs -.25), while the difference was negligible for TA.

Inconsistencies across studies are likely mirrored by cultural or educational aspects. When considering school performance, we should also take into the account the intrinsic variability of educational paths, especially in secondary education, where the frequency of math courses/ lessons (or other STEM subjects, in general) can vary considerably. Another source of 
inconsistency could be represented by use of different tests/self-reporting in different populations. For example, self-reporting measures specifically developed for assessing primary school children could emphasize the emotionality (affective) dimension of anxiety (Lowe et al., 2011; von der Embse \& Putwain, 2015; Vukovic et al., 2013b; Wu et al., 2012). At the same time, instruments developed for older students are often more focused on the cognitive ("worry") aspect of performance (Cassady \& Johnson, 2002), together with other elements (i.e. the affective dimension, physiological effects, and motivational components) (Dowker et al., 2016; Pekrun et al., 2004).

Another core theme is related to the causal pattern between math performance and academic anxiety. As children gain more experience of mathematical success and failure (or testing situations in general), academic anxiety may increase in those students whose poor performance results in repeated experiences of failure, but not to the same extent in pupils who experience greater success in mathematics (Carey et al., 2017). A recent study reported a large dissociation between cognitive and emotional math problems in primary and secondary school children (Devine et al., 2018). These findings led the question of whether MA is an overall unique proxy for these emotional problems, or whether other emotional difficulties may explain the difficulties linked to poor mathematics performance. Thus, future longitudinal studies should further evaluate the role of age in this dynamic relationship over time. Our results also call for more studies specifically targeting younger students. In the present meta-analysis, 61 studies specifically targeted primary students, out of the 111 total studies that targeted primary and secondary school students. Given the short history of research on the relationship between MA/TA and mathematics performance in young children, more research is needed to elucidate the complex connections that exist in this field. Key questions remain regarding the prevalence of academic anxiety in general, the relationship between academic anxiety and MA/ TA and math performance, as well as factors contributing to these relationships in young children.

\section{Academic Anxiety and Working Memory}

There are theoretical reasons to believe that changes in the relationships between academic anxiety and math performance could reflect developmental changes in cognitive resources, and in the ways in which they are used in mathematical situations. Research on WM suggests that performance deficits caused by anxiety can be generally summarized by the extent to which individuals are able to use their WM capacity (Darke, 1988; Eysenck, 1985). Overall, the WM system is a finite capacity system and deals with the simultaneous transitory processing and storage of information (Baddeley, 1986). According to the cognitive interference theory, during the execution of a math task, highly anxious individuals could have less available WM resources for the task solution, because anxiety (e.g. worry) is reducing the available resources and this leads to poor performance (Ashcraft \& Kirk, 2001; Eysenck, 1985; Lee, 1999). The cognitive interference theory also suggests that general academic anxiety leads to poor mathematics performance. One key mechanism of this one-way relationship is that MA/TA drains WM resources so that students do not have sufficient WM capacity for math tasks, leading to poor performance (Ashcraft \& Kirk, 2001; Eysenck \& Calvo, 1992; Miller \& Bichsel, 2004).

Our results revealed a weak but stable relationship $(-.14<r<-.19)$ between MA and WM, an effect which remains even after the trim-and-fill correction. Moderation analyses suggested that the relationship does not change according to WM type or degree of cognitive control required by WM tasks. Our mediation analyses seemed to consistently suggest that the indirect effect of MA on math achievement mediated by WM was negligible. As Namkung et al. (2019) concluded, it is no surprise to find these weak correlations between MA/TA (measured by self-report 
questionnaires) and WM, since academic anxiety should not be induced during a WM task. Furthermore, this finding may pose some interesting methodological questions to the cognitive interference theory. As previously mentioned, this theory states that during the execution of assessment tasks, anxious individuals overload their WM system with interfering worries, thus leading to a decrease in task performance. In order to effectively test this hypothesis and assess the contingent effect of WM on the relationship between academic anxiety and math, online assessment forms for both anxiety level (i.e. state anxiety) and WM resources should be implemented. This can either be achieved through experimental paradigms such as dual-task designs (Trezise \& Reeve, 2014) or even using other implicit measures such as affective priming tasks (Rubinsten et al., 2012), together with other common measures.

This work leaves another question open, namely how differences in the levels of WM may or may not influence the relationship between WM and MA/TA. There are indeed conflicting results on the negative impact of MA on math performance according to individual levels of WM resources. Some studies found that high-MA students with low working memory capacity are more predisposed to poor math performance (Ashcraft \& Kirk, 2001; Miller \& Bichsel, 2004), while others suggest instead that high-MA students with high working memory capacity are more inclined to fail math tasks (Beilock \& DeCaro, 2007; Ramirez et al., 2013). A better understanding of the modulating influence of WM domains (i.e. verbal $v s$ visuospatial), or degree of cognitive control required (i.e. STM vs WM), may help shed some light on this conundrum. Thus, future studies are needed to explore domain specificity and MA/TA-WM interaction hypotheses, as well as how these elements can affect the relationship between MA and mathematics performance.

\section{Conclusion}

The current meta-analysis provides an up-to-date synthesis on the relationship between MA/TA and math performance. Our results confirm that both forms of academic anxiety (MA and TA) are negatively related to math achievement not only in school age individuals, but also in adulthood. In terms of MA, the strength of this connection is strongly influenced by the type of math task and by gender differences; however, this influence is lower in TA studies. In addition, WM proved to be a stable, albeit weak, mediator in the relationship between both academic anxiety forms and math performance, confirming the key role of this cognitive construct. There was no substantial evidence on whether the type of WM components or the level of cognitive control can influence the relationship. Future studies are needed to clarify this point, as well as to map any potential developmental changes in the relationship of academic anxiety and math performance.

Supplementary Information The online version contains supplementary material available at https://doi.org/ 10.1007/s10648-021-09618-5.

Acknowledgements SC was supported by the European Union's Horizon 2020 research and innovation programme under the Marie Sklodowska-Curie grant agreement No. 700031.

Data Availability The data and associated files for this meta-analysis are available at https://osf.io/73pmb/

Funding Open access funding provided by Università degli Studi di Padova within the CRUI-CARE Agreement. 


\section{Declarations}

Conflict of Interest The authors declare no competing interests.

Open Access This article is licensed under a Creative Commons Attribution 4.0 International License, which permits use, sharing, adaptation, distribution and reproduction in any medium or format, as long as you give appropriate credit to the original author(s) and the source, provide a link to the Creative Commons licence, and indicate if changes were made. The images or other third party material in this article are included in the article's Creative Commons licence, unless indicated otherwise in a credit line to the material. If material is not included in the article's Creative Commons licence and your intended use is not permitted by statutory regulation or exceeds the permitted use, you will need to obtain permission directly from the copyright holder. To view a copy of this licence, visit http://creativecommons.org/licenses/by/4.0/.

\section{References}

References marked with a single asterisk indicate effect sizes included in the present metaanalysis.

*Abu-Hilal, M. M. (2000). A structural model for predicting mathematics achievement: Its relation with anxiety and self-concept in mathematics. Psychological Reports, 86(3), 835-847. doi: https://doi.org/10.2466/pr0. 2000.86.3.835

Ahmed, W. (2018). Developmental trajectories of math anxiety during adolescence: Associations with STEM career choice. Journal of adolescence, 67, 158-166. https://doi.org/10.1016/j.adolescence.2018.06.010.

*Ahmed, W., Minnaert, A., van der Werf, G., \& Kuyper, H. (2010). Perceived social support and early adolescents' achievement: The mediational roles of motivational beliefs and emotions. Journal of youth and adolescence, 39(1), 36. doi: https://doi.org/10.1007/s10964-008-9367-7

*Allen, M., \& Vallée-Tourangeau, F. (2016). Interactivity defuses the impact of mathematics anxiety in primary school children. International Journal of Science and Mathematics Education, 14(8), 1553-1566. doi: https://doi.org/10.1007/s10763-015-9659-9

Aiken, L. R. (1970). Attitudes toward mathematics. Review of educational research, 40(4), 551-596. https://doi. org/10.3102/00346543040004551.

*Allred, G. (2018). Examining the influence of executive resources and mathematical abilities on framing biases (Publication No. 3207) [Doctoral dissertation, University of Nevada]. UNLV Theses, Dissertations, Professional Papers, and Capstones. https://digitalscholarship.unlv.edu/thesesdissertations/3207.

Appel, M., Kronberger, N., \& Aronson, J. (2011). Stereotype threat impairs ability building: Effects on test preparation among women in science and technology. European Journal of Social Psychology, 41(7), 904 913. https://doi.org/10.1002/ejsp.835.

*Araki, N. (1992). Test anxiety in elementary school and junior high school students in japan. Anxiety, Stress, \& Coping, 5(3), 205-215. doi: https://doi.org/10.1080/10615809208249522

*Arens, A. K., Becker, M., \& Möller, J. (2017). Social and dimensional comparisons in math and verbal test anxiety: Within- and cross-domain relations with achievement and the mediating role of academic self-concept. Contemporary Educational Psychology, 51, 240-252. doi: https://doi.org/10.1016/j.cedpsych.2017.08.005

Ayres, P. L. (2001). Systematic mathematical errors and cognitive load. Contemporary Educational Psychology, 26(2), 227-248. https://doi.org/10.1006/ceps.2000.1051.

Ashcraft, M. H. (2002). Math anxiety: Personal, educational, and cognitive consequences. Current Directions in Psychological Science, 11(5), 181-185. https://doi.org/10.1111/1467-8721.00196.

Ashcraft, M. H., \& Faust, M. W. (1994). Mathematics anxiety and mental arithmetic performance: An exploratory investigation. Cognition \& Emotion, 8(2), 97-125. https://doi.org/10.1080/02699939408408931.

*Ashcraft, M. H., \& Kirk, E. P. (2001). The relationships among working memory, math anxiety, and performance. Journal of Experimental Psychology: General, 130(2), 224-237. doi: https://oi.org/10. 1037/0096-3445.130.2.224

Ashcraft, M. H., \& Krause, J. A. (2007). Working memory, math performance, and math anxiety. Psychonomic Bulletin and Review, 14(2), 243-248. https://doi.org/10.3758/BF03194059.

Ashcraft, M. H., \& Moore, A. M. (2009). Mathematics anxiety and the affective drop in performance. Journal of Psychoeducational Assessment, 27(3), 197-205. https://doi.org/10.1177/0734282908330580. 
Ashcraft, M. H., \& Ridley, K. S. (2005). Math anxiety and its cognitive consequences. In J. I. D. Campbell (Ed.), Handbook of Mathematical Cognition (pp. 315-327). Psychology Press.

Ashcraft, M. H., \& Rudig, N. O. (2012). Higher cognition is altered by noncognitive factors: How affect enhances and disrupts mathematics performance in adolescence and young adulthood. In V. F. Reyna, S. B. Chapman, M. R. Dougherty, \& J. Confrey (Eds.), The adolescent brain: Learning, reasoning, and decision making (pp. 243-263). American Psychological Association. https://doi.org/10.1037/13493-009.

*Awofala, A. (2014). Examining personalisation of instruction, attitudes toward and achievement in mathematics word problems among Nigerian senior secondary school students. International Journal of Education in Mathematics Science and Technology, 2(4), 273-288.

Baddeley, A., \& Hitch, G. (1974). Working memory. In G. A. Bower (Ed.), The psychology of learning and motivation (pp. 47-90). Academic Press.

Baddeley, A. D. (1986). Working memory (Vol. 11). Oxford University Press.

*Bai, H. (2011). Cross-validating a bidimensional mathematics anxiety scale. Assessment, 18(1), 115-122. doi: https://doi.org/10.1177/1073191110364312

*Bagley, J. (2015). Factors related to successful completion of developmental mathematics courses (Publication No. 10108115) [Doctoral dissertation, Utah State University]. ProQuest Dissertations Publishing. https:// www.proquest.com/openview/4e4291c91ac96e0cdbbe25667e2d798b/1?pq-origsite=gscholar\&cbl=18750.

Bandalos, D. L., Yates, K., \& Thorndike-Christ, T. (1995). Effects of math self-concept, perceived self-efficacy, and attributions for failure and success on test anxiety. Journal of Educational Psychology, 87(4), 611-623. https://doi.org/10.1037/0022-0663.87.4.611.

*Barnett, P. A. (2012). High school students' academic buoyancy: Longitudinal changes in motivation, cognitive engagement, and affect in English and math (Publication No. AAI3494306) [Doctoral dissertation, Fordham University]. Fordham Research Commons. https://research.library.fordham.edu/dissertations/AAI3494306.

Barroso, C., Ganley, C. M., McGraw, A. L., Geer, E. A., Hart, S. A., \& Daucourt, M. C. (2021). A meta-analysis of the relation between math anxiety and math achievement. Psychological Bulletin, 147(2), 134. https://doi. org/10.1037/bul0000307.

*Baya'a, N. F. (1990). Mathematics anxiety, mathematics achievement, gender, and socio-economic status among Arab secondary students in Israel. International Journal of Mathematical Education in Science and Technology, 21(2), 319-324. doi: https://doi.org/10.1080/0020739900210221

*Beasley, T. M., Long, J. D., \& Natali, M. (2001). A confirmatory factor analysis of the mathematics anxiety scale for children. Measurement and Evaluation in Counseling and Development, 34(1), 14-26. doi: https:// doi.org/10.1080/07481756.2001.12069019

Beilock, S. L., \& Carr, T. H. (2005). When high-powered people fail: Working memory and "Choking under pressure" in math. Psychological Science, 16(2), 101-105. https://doi.org/10.1111/j.0956-7976.2005.00789.x.

Beilock, S. L., \& DeCaro, M. S. (2007). From poor performance to success under stress: Working memory, strategy selection, and mathematical problem solving under pressure. Journal of Experimental Psychology: Learning Memory and Cognition, 33(6), 983-998. https://doi.org/10.1037/0278-7393.33.6.983.

*Bezzina, F. H. (2010). Investigating gender differences in mathematics performance and in self-regulated learning: An empirical study from Malta. Equality, Diversity and Inclusion: An International Journal, 29(7), 669-693. doi: https://doi.org/10.1108/02610151011074407

*Birenbaum, M., \& Gutvirtz, Y. (1993). The relationship between test anxiety and seriousness of errors in algebra. Journal of Psychoeducational Assessment, 11(1), 12-19. doi: https://doi.org/10.1177/ 073428299301100102

*Birgin, O., Baloğlu, M., Çatlioğlu Hakan, H., \& Gürbüz Ramazan, R. (2010). An investigation of mathematics anxiety among sixth through eighth grade students in Turkey. Learning and Individual Differences, 20(6), 654-658. doi: https://doi.org/10.1016/j.lindif.2010.04.006

*Bong, M., Cho, C., Ahn, H. S., \& Kim, H. J. (2012). Comparison of self-beliefs for predicting student motivation and achievement. Journal of Educational Research, 105(5), 336-352. doi: https://doi.org/10. 1080/00220671.2011.627401

Borenstein, M., Hedges, L., Higgins, J., \& Rothstein, H. (2009). Introduction to meta-analysis. John Wiley \& Sons, Ltd.

*Bosmans, G., \& De Smedt, B. (2015). Insecure attachment is associated with math anxiety in middle childhood. Frontiers in Psychology, 6. doi: https://doi.org/10.3389/fpsyg.2015.01596

*Braham, E. J., \& Libertus, M. E. (2018). When approximate number acuity predicts math performance: The moderating role of math anxiety. PLOS ONE, 13(5), e0195696. doi: https://doi.org/10.1371/journal.pone.0195696

*Buelow, M. T., \& Frakey, L. L. (2013). Math anxiety differentially affects WAIS-IV arithmetic performance in undergraduates. Archives of Clinical Neuropsychology, 28(4), 356-362. doi: https://doi.org/10.1093/arclin/act006

*Calvo, M. G., Ramos, P. M., \& Estevez, A. (1992). Test anxiety and comprehension efficiency: The role of prior knowledge and working memory deficits. Anxiety, Stress, \& Coping, 5(2), 125-138. doi: https://oi. org/10.1080/10615809208250492 
*Carey, E., Devine, A., Hill, F., \& Szücs, D. (2017). Differentiating anxiety forms and their role in academic performance from primary to secondary school. PLOS ONE, 12(3), e0174418. doi: https://doi.org/10.1371/ journal.pone. 0174418

*Cargnelutti, E., Tomasetto, C., \& Passolunghi, M. C. (2017a). How is anxiety related to math performance in young students? A longitudinal study of Grade 2 to Grade 3 children. Cognition and Emotion, 31(4), 755764. doi: https://doi.org/10.1080/02699931.2016.1147421

*Cargnelutti, E., Tomasetto, C., \& Passolunghi, M. C. (2017b). The interplay between affective and cognitive factors in shaping early proficiency in mathematics. Trends in Neuroscience and Education, 8, 28-36.

*Casad, B. J., Hale, P., \& Wachs, F. L. (2015). Parent-child math anxiety and math-gender stereotypes predict adolescents' math education outcomes. Frontiers in Psychology, 6. doi: https://doi.org/10.3389/fpsyg.2015.01597

*Casey, M. B., Nuttall, R. L., \& Pezaris, E. (1997). Mediators of gender differences in mathematics college entrance test scores: A comparison of spatial skills with internalized beliefs and anxieties. Developmental Psychology, 33(4), 669-680. doi: https://doi.org/10.1037/0012-1649.33.4.669

Cassady, J. C. (2010). Test anxiety: Contemporary theories and implications for learning. In J. C. Cassady (Ed.), Anxiety in schools: The causes, consequences, and solutions for academic anxieties (pp. 7-26). Peter Lang.

Cassady, J. C., \& Johnson, R. E. (2002). Cognitive test anxiety and academic performance. Contemporary Educational Psychology, 27, 270-295. https://doi.org/10.1006/ceps.2001.1094.

Caviola, S., Mammarella, I. C., Cornoldi, C., \& Lucangeli, D. (2012). The involvement of working memory in children's exact and approximate mental addition. Journal of experimental child psychology, 112(2), 141160. https://doi.org/10.1016/j.jecp.2012.02.005.

*Caviola, S., Primi, C., Chiesi, F., \& Mammarella, I. C. (2017). Psychometric properties of the Abbreviated Math Anxiety Scale (AMAS) in Italian primary school children. Learning and Individual Differences, 55, 174 182. doi: https://doi.org/10.1016/j.lindif.2017.03.006

Caviola, S., Mammarella, I. C., Pastore, M., \& LeFevre, J. A. (2018). Children's strategy choices on complex subtraction problems: Individual differences and developmental changes. Frontiers in Psychology, 9, 1209.

*Chang, H. S. (2017). The Role of Anticipation in the Relation Between Math Anxiety and Math Performance (Publication No. 10266641) [Doctoral dissertation, The University of Chicago]. ProQuest Dissertations Publishing.

*Cheema, J. R., \& Sheridan, K. (2015). Time spent on homework, mathematics anxiety and mathematics achievement: Evidence from a US sample. Issues in Educational Research, 25(3), 246.

*Ching, B. H. H. (2017). Mathematics anxiety and working memory: Longitudinal associations with mathematical performance in Chinese children. Contemporary Educational Psychology, 51, 99-113. doi: https:/doi. org/10.1016/j.cedpsych.2017.06.006

Chiu, L. H., \& Henry, L. L. (1990). Development and validation of the Mathematics Anxiety Scale for Children. Measurement and evaluation in counseling and development, 23(3), 121-127.

*Ciftci, S. K. (2015). Effects of secondary school students' perceptions of mathematics education quality on mathematics anxiety and achievement. Educational Sciences: Theory and Practice, 15(6), 1487-1501.

Cornoldi, C., \& Giofrè, D. (2014). The crucial role of working memory in intellectual functioning. European Psychologist, 19(4), 260-268. https://doi.org/10.1027/1016-9040/a000183.

Cowan, N. (2016). Working memory capacity: Classic edition. Routledge. https://doi.org/10.4324/ 9781315625560 .

Cvencek, D., Meltzoff, A. N., \& Kapur, M. (2014). Cognitive consistency and math-gender stereotypes in Singaporean children. Journal of experimental child psychology, 117, 73-91. https://doi.org/10.1016/j.jecp. 2013.07.018.

*Daches-Cohen, L., \& Rubinsten, O. (2017). Mothers, intrinsic math motivation, arithmetic skills, and math anxiety in elementary school. Frontiers in Psychology, 8. doi: https://doi.org/10.3389/fpsyg.2017.01939

Darke, S. (1988). Anxiety and working memory capacity. Cognition and Emotion, 2(2), 145-154. https://doi.org/ 10.1080/02699938808408071.

Derakshan, N., \& Eysenck, M. W. (2009). Anxiety, processing efficiency and cognitive performance: New developments from attentional control theory. European Psychologist, 14, 168-176. https://doi.org/10.1027/ 1016-9040.14.2.168.

Derakshan, N., \& Eysenck, M. W. (2011). New perspectives in attentional control theory. Personality and Individual Differences, 50, 955-960. https://doi.org/10.1016/j.paid.2010.08.019.

*Devine, A., Fawcett, K., Szücs, D., \& Dowker, A. (2012). Gender differences in mathematics anxiety and the relation to mathematics performance while controlling for test anxiety. Behavioral and Brain Functions, 8(1), 33. doi: https://doi.org/10.1186/1744-9081-8-33

*Devine, A., Hill, F., Carey, E., \& Szucs, D. (2018). Cognitive and emotional math problems largely dissociate: Prevalence of developmental dyscalculia and mathematics anxiety. Journal of Educational Psychology, 110(3), 431-444. doi: https://doi.org/10.1037/edu0000222 
Donolato, E., Toffalini, E., Giofrè, D., Caviola, S., \& Mammarella, I. C. (2020). Going beyond mathematics anxiety in primary and middle school students: The role of ego-resiliency in mathematics. Mind, Brain, and Education, 14(3), 255-266. https://doi.org/10.1111/mbe.12251.

Dowker, A. (2005). Early identification and intervention for students with mathematics difficulties. Journal of learning disabilities, 38(4), 324-332. https://doi.org/10.1177/00222194050380040801.

Dowker, A. (2015). Individual differences in arithmetical abilities: The componential nature of arithmetic. In R. C. Kadosh \& A. Dowker (Eds.), Oxford library of psychology. The Oxford handbook of numerical cognition (pp. 878-894). Oxford University Press.

Dowker, A., Sarkar, A., \& Looi, C. Y. (2016). Mathematics anxiety: What have we learned in 60 years? Frontiers in Psychology, 7, 508. https://doi.org/10.3389/fpsyg.2016.00508.

Duckworth, A. L., Quinn, P. D., \& Tsukayama, E. (2012). What no child left behind leaves behind: The roles of IQ and self-control in predicting standardized achievement test scores and report card grades. Journal of Educational Psychology, 104(2), 439. https://doi.org/10.1037/a0026280.

*Durette, R. (2011). Operation span task's susceptibility to math anxiety: Support from fluid intelligence (Publication No. 1002) [Doctoral dissertation, University of Nevada]. UNLV Theses, Dissertations, Professional Papers, and Capstones. https://digitalscholarship.unlv.edu/thesesdissertations/1002/.

*Dutko, J. A. (2015). Understanding mathematics anxiety: The relationships between fourth grade students' math anxiety, multiplication fact fluency, and problem solving ability [Doctoral dissertation, Liberty University]. ProQuest Dissertations Publishing. https://www.proquest.com/openview/ f6d74e04cb2f3fa4cd0475d940137bfa/1?pq-origsite=gscholar\&cbl=18750\&diss=y.

Duval, S. J. (2005). The trim and fill method. In H. R. Rothstein, A. J. Sutton, \& M. Borenstein (Eds.), Publication bias in meta-analysis: Prevention, assessment, and adjustments (pp. 127-144). Wiley.

Elliot, A. J., \& McGregor, H. A. (1999). Test anxiety and the hierarchical model of approach and avoidance achievement motivation. Journal of Personality and Social Psychology, 76(4), 628-644. https://doi.org/10. 1037/0022-3514.76.4.628.

Else-Quest, N. M., Hyde, J. S., \& Linn, M. C. (2010). Cross-national patterns of gender differences in mathematics: A meta-analysis. Psychological bulletin, 136(1), 103-127. https://doi.org/10.1037/a0018053.

*Engelhard Jr, G. (1990). Gender differences in performance on mathematics items: Evidence from the United States and Thailand. Contemporary Educational Psychology, 15(1), 13-26. doi: https://doi.org/10.1016/ 0361-476X(90)90002-I

*Engelhard, G. (1990). Math anxiety, mother's education, and the mathematics performance of adolescent boys and girls: Evidence from the United States and Thailand. Journal of Psychology: Interdisciplinary and Applied, 124(3), 289-298. doi: https://doi.org/10.1080/00223980.1990.10543224

Engle, R. W., \& Kane, M. J. (2004). Executive attention, working memory capacity, and a two-factor theory of cognitive control. In B. H. Ross (Ed.), Psychology of learning and motivation (Vol. 44, pp. 145-200). Elsevier Academic Press.

*Erturan, S., \& Jansen, B. (2015). An investigation of boys' and girls' emotional experience of math, their math performance, and the relation between these variables. European Journal of Psychology of Education, 30(4), 421-435. doi: https://doi.org/10.1007/s10212-015-0248-7

Evans, J. (2000). Adults' mathematical thinking and emotions: A study of numerate practice. Routledge.

Eysenck, M. W. (1985). Anxiety and cognitive-task performance. Personality and Individual differences, 6(5), 579-586. https://doi.org/10.1016/0191-8869(85)90007-8.

Eysenck, M. W., \& Calvo, M. G. (1992). Anxiety and performance: The processing efficiency theory. Cognition \& Emotion, 6(6), 409-434. https://doi.org/10.1080/02699939208409696.

Eysenck, M. W., Derakshan, N., Santos, R., \& Calvo, M. G. (2007). Anxiety and cognitive performance: Attentional control theory. Emotion, 7, 336-353. https://doi.org/10.1037/1528-3542.7.2.336.

*Federici, R. A., \& Skaalvik, E. M. (2014). Students' perceptions of emotional and instrumental teacher support: Relations with motivational and emotional responses. International Education Studies, 7(1). doi: https:/doi. org/10.5539/ies.v7n1p21

Ferguson, A. M., Maloney, E. A., Fugelsang, J., \& Risko, E. F. (2015). On the relation between math and spatial ability: The case of math anxiety. Learning and Individual Differences, 39, 1-12. https://doi.org/10.1016/j. lindif.2015.02.007.

*Ferla, J., Valcke, M., \& Cai, Y. (2009). Academic self-efficacy and academic self-concept: Reconsidering structural relationships. Learning and individual differences, 19(4), 499-505. doi: https://doi.org/10.1016/j. lindif.2009.05.004

*Field, T. M. (2011). California High School Exit Exam for students with disabilities: The impact of setting, anxiety, and stereotype threat on stuents' math performance (Publication No. 282) [Doctoral dissertation, University of San Francisco]. USF Scholarship: a digital repository @ Gleeson Library | Geschke Center. https://repository.usfca.edu/diss/282. 
Flore, P. C., \& Wicherts, J. M. (2015). Does stereotype threat influence performance of girls in stereotyped domains? A meta-analysis. Journal of school psychology, 53(1), 25-44. https://doi.org/10.1016/j.jsp.2014. 10.002 .

Foley, A. E., Herts, J. B., Borgonovi, F., Guerriero, S., Levine, S. C., \& Beilock, S. L. (2017). The math anxietyperformance link: A global phenomenon. Current Directions in Psychological Science, 26(1), 52-58. https:// doi.org/10.1177/0963721416672463.

*Fonteyne, L., Duyck, W., \& De Fruyt, F. (2017). Program-specific prediction of academic achievement on the basis of cognitive and non-cognitive factors. Learning and Individual Differences, 56, 34 48. doi: https:// doi.org/10.1016/j.lindif.2017.05.003

Fredricks, J. A., \& Eccles, J. S. (2002). Children's competence and value beliefs from childhood through adolescence: growth trajectories in two male-sex-typed domains. Developmental Psychology, 38(4), 519533. https://doi.org/10.1037/0012-1649.38.4.519.

*Frenzel, A. C., Thrash, T. M., Pekrun, R., \& Goetz, T. (2007). Achievement emotions in Germany and China. Journal of Cross-Cultural Psychology, 38(3), 302-309. doi: https://doi.org/10.1177/0022022107300276

*Ganley, C. M. (2011). Gender Differences in Math Performance Across Development: Exploring the Roles of Anxiety, Working Memory, and Stereotype Threat (Publication No. 2345/1982) [Doctoral dissertation, Boston College]. eScholarship@BC, Boston College University Libraries. http://hdl.handle.net/2345/1982

*Ganley, C. M., \& McGraw, A. L. (2016). The development and validation of a revised version of the math anxiety scale for young children. Frontiers in Psychology, 7. doi: https://doi.org/10.3389/fpsyg.2016.01181

*Ganley, C. M., \& Vasilyeva, M. (2014). The role of anxiety and working memory in gender differences in mathematics. Journal of Educational Psychology, 106(1), 105-120. https://doi.org/10.1037/a0034099

*Georges, C., Hoffmann, D., \& Schiltz, C. (2016). How math anxiety relates to number-space associations. Frontiers in psychology, 7, 1401. doi: https://doi.org/10.3389/fpsyg.2016.01401

Gerwing, T. G., Rash, J. A., Gerwing, A. M. A., Bramble, B., \& Landine, J. (2015). Perceptions and incidence of test anxiety. The Canadian Journal for Scholarship of Teaching and Learning, 6, Article3, 1-14. doi:https:// doi.org/10.5206/cjsotl-rcacea.2015.3.3

*Gibson-Dee, K. (2016). Hope, expectation, math anxiety, and achievement in college algebra students: examining an instructional strategy using multi-level modeling (Publication No. 6506) [Doctoral dissertation, University of South Florida]. University of South Florida Scholar Commons. https://scholarcommons. usf.edu/etd/6506.

*Gierl, M. J., \& Bisanz, J. (1995). Anxieties and attitudes related to mathematics in grades 3 and 6. Journal of Experimental Education, 63(2), 139-158. doi: https://doi.org/10.1080/00220973.1995.9943818

Gierl, M. J., \& Rogers, W. T. (1996). A confirmatory factor analysis of the test anxiety inventory using Canadian high school, students. Educational and Psychological Measurement, 56(2), 315-324. https://doi.org/10. 1177/0013164496056002012.

Goetz, T., Bieg, M., Lüdtke, O., Pekrun, R., \& Hall, N. C. (2013). Do girls really experience more anxiety in mathematics? Psychological Science, 24(10), 2079-2087. https://doi.org/10.1177/0956797613486989.

*Goetz, T., Frenzel, A. C., Ludtke, O., \& Hall, N. C. (2010). Between-domain relations of academic emotions: Does having the same instructor make a difference? Journal of Experimental Education, 79(1), 84-101. doi: https://doi.org/10.1080/00220970903292967

*Goetz, T., Frenzel, A. C., Pekrun, R., \& Hall, N. C. (2006). The domain specificity of academic emotional experiences. Journal of Experimental Education, 75(1), 5-29. doi: https://doi.org/10.3200/JEXE.75.1.5-29

*Goetz, T., Frenzel, A. C., Pekrun, R., Hall, N. C., \& Lüdtke, O. (2007). Between-and within-domain relations of students' academic emotions. Journal of Educational Psychology, 99(4), 715. doi: https://doi.org/10.1037/ 0022-0663.99.4.715

*Gogol, K., Brunner, M., Preckel, F., Goetz, T., \& Martin, R. (2016). Developmental dynamics of general and school-subject-specific components of academic self-concept, academic interest, and academic anxiety. Frontiers in Psychology, 7. doi: https://doi.org/10.3389/fpsyg.2016.00356

*Grays, S. D., Rhymer, K. N., \& Swartzmiller, M. D. (2017). Moderating effects of mathematics anxiety on the effectiveness of explicit timing. Journal of Behavioral Education, 26(2), 188-200. doi: https://doi.org/10. 1007/s10864-016-9251-6

Gregor, A. (2005). Examination anxiety: Live with it, control it or make it work for you? School Psychology International, 26(5), 617-635. https://doi.org/10.1177/0143034305060802.

*Gunderson, E. A., Park, D., Maloney, E. A., Beilock, S. L., \& Levine, S. C. (2018). Reciprocal relations among motivational frameworks, math anxiety, and math achievement in early elementary school. Journal of Cognition and Development, 19(1), 21-46. doi: https://doi.org/10.1080/15248372.2017.1421538

*Guven, B., \& Cabakcor, B. O. (2013). Factors influencing mathematical problem-solving achievement of seventh grade Turkish students. Learning and Individual Differences, 23(1), 131-137. doi: https://doi.org/ 10.1016/j.lindif.2012.10.003 
Hamid, M. H. S., Shahrill, M., Matzin, R., Mahalle, S., \& Mundia, L. (2013). Barriers to mathematics achievement in Brunei secondary school students: Insights into the roles of mathematics anxiety, self-esteem, proactive coping, and test stress. International Education Studies, 6(11), 1-14. https://doi.org/10.5539/ies.v6n11p1.

*Hannon, B. (2012). Test anxiety and performance-avoidance goals explain gender differences in SAT-V, SATM, and overall SAT scores. Personality and individual differences, 53(7), 816-820. doi: https://doi.org/10. 1016/j.paid.2012.06.003

*Hannon, B. (2015). Hispanics' SAT scores: The influences of level of parental education, performanceavoidance goals, and knowledge about learning. Hispanic journal of behavioral sciences, 37(2), $204-222$. doi: https://doi.org/10.1177/0739986315573249

*Hannon, B., \& McNaughton-Cassill, M. (2011). SAT performance: Understanding the contributions of cognitive/learning and social/personality factors. Applied Cognitive Psychology, 25(4), 528-535. doi: https://doi.org/10.1002/acp.1725

*Harari, R. R., Vukovic, R. K., \& Bailey, S. P. (2013). Mathematics anxiety in young children: An exploratory study. Journal of Experimental Education, 81(4), 538-555. doi: https://doi.org/10.1080/00220973.2012.727888

*Hart, S. A., Logan, J. A. R., Thompson, L., Kovas, Y., McLoughlin, G., Petrill SA (2016). A latent profile analysis of math achievement, numerosity, and math anxiety in twins. Journal of Educational Psychology, 108(2), 181-193. doi: https://doi.org/10.1037/edu0000045

*Haynes, A. F., Mullins, A. G., \& Stein, B. S. (2004). Differential models for math anxiety in male and female college students. Sociological Spectrum, 24(3), 295-318. doi: https://doi.org/10.1080/02732170490431304

*Helming, L. (2013). Motivation and math anxiety for ability grouped college math students (Publication No. 3599873) [Doctoral dissertation, The University of South Dakota]. ProQuest Dissertations Publishing. https://eric.ed.gov/?id=ED563200.

Hembree, R. (1988). Correlates, causes, effects, and treatment of test anxiety. Review of Educational Research, 58(1), 47-77. https://doi.org/10.3102/00346543058001047.

Hembree, R. (1990). The nature, effects, and relief of mathematics anxiety. Journal for Research in Mathematics Education, 21(1), 33-46. https://doi.org/10.2307/749455.

*Henry, A. (2017). The role of math anxiety and situational anxiety in math performance (Publication No. 153) [Doctoral dissertation, University of Chicago]. Knowledge UChicago. https://knowledge.uchicago.edu/ record $/ 153$

*Henschel, S., \& Roick, T. (2017). Relationships of mathematics performance, control and value beliefs with cognitive and affective math anxiety. Learning and Individual Differences, 55, 97-107. doi: https://doi.org/ 10.1016/j.lindif.2017.03.009

Higgins, J. P., Thompson, S. G., Deeks, J. J., \& Altman, D. G. (2003). Measuring inconsistency in meta-analyses. British Medical Journal, 327, 557-560. https://doi.org/10.1136/bmj.327.7414.557.

*Hill, F., Mammarella, I. C., Devine, A., Caviola, S., Passolunghi, M. C., \& Szucs, D. (2016). Maths anxiety in primary and secondary school students: Gender differences, developmental changes and anxiety specificity. Learning and Individual Differences, 48, 45-53. doi: https://doi.org/10.1016/j.lindif.2016.02.006

Hill, K. T., \& Sarason, S. B. (1966). The relation of test anxiety and defensiveness to test and school performance over the elementary school years: a further longitudinal study. Monographs of the Society for Research in Child Development, 31(2), 1-76. https://doi.org/10.2307/1165770.

*Hodge, M. B. (1997). Effects of gender, math self-efficacy, test anxiety, and previous math achievement on posology errors of baccalaureate nursing students (Publication No. 9733068) [Doctoral dissertation, University of Southern California]. ProQuest Dissertations Publishing. https://www.proquest.com/ openview/963339be131be2d3ad0c153f9485da1c/1?pq-origsite=gscholar\&cbl=18750\&diss=y.

*Hoferichter, F., Raufelder, D., Ringeisen, T., Rohrmann, S., \& Bukowski, W. M. (2015). Assessing the multifaceted nature of test anxiety among secondary school students: An English version of the German test anxiety questionnaire: PAF-E. Journal of Psychology: Interdisciplinary and Applied, 150(4), 450-468. doi: https://doi.org/10.1080/00223980.2015.1087374

*Hoffman, B. (2010). "I think I can, but I'm afraid to try": The role of self-efficacy beliefs and mathematics anxiety in mathematics problem-solving efficiency. Learning and individual differences, 20(3), 276-283. doi: https://doi.org/10.1016/j.lindif.2010.02.001

*Hong, E., \& Karstensson, L. (2002). Antecedents of state test anxiety. Contemporary Educational Psychology, 27(2), 348-367. doi: https://doi.org/10.1006/ceps.2001.1095

*Hunt, T. E., \& Sandhu, K. K. (2017). Endogenous and exogenous time pressure: Interactions with mathematics anxiety in explaining arithmetic performance. International Journal of Educational Research, 82, 91-98. doi: https://doi.org/10.1016/j.ijer.2017.01.005

*Imbo, I., \& Vandierendonck, A. (2007a). The development of strategy use in elementary school children: Working memory and individual differences. Journal of Experimental Child Psychology, 96(4), 284-309. doi: https://doi.org/10.1016/j.jecp.2006.09.001 
*Imbo, I., \& Vandierendonck, A. (2007b). Effects of problem size, operation, and working-memory span on simple-arithmetic strategies: Differences between children and adults? Psychological Research, 72(3), 331346. doi: https://doi.org/10.1007/s00426-007-0112-8

*Iossi, L. H. (2009). The Mathematics Anxiety of Bilingual Community College Students (Publication No. 198) [Doctoral dissertation, Florida International University]. Florida International University Digital Commons. https://digitalcommons.fiu.edu/etd/198.

Jameson, M. M. (2014). Contextual factors related to math anxiety in second-grade children. Journal of Experimental Education, 82(4), 518-536. https://doi.org/10.1080/00220973.2013.813367.

*Jansen, B. R. J., Schmitz, E. A., \& van der Maas, H. L. J. (2016). Affective and motivational factors mediate the relation between math skills and use of math in everyday life. Frontiers in Psychology, 7, 513. doi: https:// doi.org/10.3389/fpsyg.2016.00513

*Justicia-Galiano, M. J., Martín-Puga, M. E., Linares, R., \& Pelegrina, S. (2017). Math anxiety and math performance in children: The mediating roles of working memory and math self-concept. British Journal of Educational Psychology, 87(4), 573-589. doi: https://doi.org/10.1111/bjep.12165

*Justicia-Galiano, M.-J., Pelegrina, S., Lechuga, M.-T., Gutiérrez-Palma, N., Martín-Puga, E.-M., \& Lendínez, C. (2016). Math anxiety and its relationship to inhibitory abilities and perceived emotional intelligence. 32 , 125-131. doi: https://doi.org/10.6018/analesps.32.1.194891

*Kaba, Y., \& Şengül, S. (2018). The relationship between middle school students' mathematics anxiety and their mathematical understanding. Pegem Eğitim Ve Öğretim Dergisi, 8(3), 599-622. doi: https://doi.org/10. 14527/pegegog.2018.023

*Kalaycioglu, D. B. (2015). The influence of socioeconomic status, self-efficacy, and anxiety on mathematics achievement in England, Greece, Hong Kong, the Netherlands, Turkey, and the USA. Educational Sciences: Theory and Practice, 15(5), 1391-1401.

Karimi, A., \& Venkatesan, S. (2009). Mathematics anxiety, mathematics performance and academic hardiness in high school students. International Journal of Educational Sciences, 1(1), 33-37. https://doi.org/10.1080/ 09751122.2009.11889973.

*Karjanto, N., \& Yong, S. T. (2013). Test anxiety in mathematics among early undergraduate students in a British university in Malaysia. European Journal of Engineering Education, 38(1), 11-37. doi: https:/doi. org/10.1080/03043797.2012.742867

*Kim, C., Park, S. W., \& Cozart, J. (2014). Affective and motivational factors of learning in online mathematics courses. British Journal of Educational Technology, 45(1), 171-185. doi: https://doi.org/10.1111/j.14678535.2012.01382.x

*Kimber, C. T. (2009). The effect of training in self-regulated learning on math anxiety and achievement among preservice elementary teachers in a freshman course in mathematics concepts (Publication No. 3359748) [Doctoral dissertation, Temple University]. ProQuest Dissertations Publishing. https://www.proquest.com/ docview $/ 305016970$ ?pq-origsite $=$ gscholar $\&$ fromopenview $=$ true.

Krinzinger, H., Kaufmann, L., \& Willmes, K. (2009). Math anxiety and math ability in early primary school years. Journal of Psychoeducational Assessment, 27(3), 206-225. https://doi.org/10.1177/ 0734282908330583 .

Korhonen, J., Nyroos, M., Jonsson, B., \& Eklöf, H. (2018). Additive and multiplicative effects of working memory and test anxiety on mathematics performance in grade 3 students. Educational Psychology, 38(5), 572-595. https://doi.org/10.1080/01443410.2017.1356449.

*Kyttälä, M., \& Björn, P. M. (2014). The role of literacy skills in adolescents' mathematics word problem performance: Controlling for visuo-spatial ability and mathematics anxiety. Learning and Individual Differences, 29, 59-66. doi: https://doi.org/10.1016/j.lindif.2013.10.010

Lee, J. H. (1999). Test anxiety and working memory. Journal of Experimental Education, 67(3), 218-240. https://doi.org/10.1080/00220979909598354.

*Lee, K., \& Cho, S. (2018). Magnitude processing and complex calculation is negatively impacted by mathematics anxiety while retrieval-based simple calculation is not. International Journal of Psychology, 53(4), 321-329. doi: https://doi.org/10.1002/ijop.12412

*Lichtenfeld, S., Pekrun, R., Stupnisky, R. H., Reiss, K., \& Murayama, K. (2012). Measuring students' emotions in the early years: The Achievement Emotions Questionnaire-Elementary School (AEQ-ES). Learning and Individual Differences, 22(2), 190-201. doi: https://doi.org/10.1016/j.lindif.2011.04.009

Liebert, R. M., \& Morris, L. W. (1967). Cognitive and emotional components of test anxiety: A distinction and some initial data. Psychological Reports, 20(3), 975-978. https://doi.org/10.2466/pr0.1967.20.3.975.

*Lim, S. Y., \& Chapman, E. (2013). An investigation of the Fennema-Sherman mathematics anxiety subscale. Measurement and Evaluation in Counseling and Development, 46(1), 26-37. doi: https://doi.org/10.1177/ 0748175612459198 
*Lim, S. Y., \& Chapman, E. (2015). Identifying affective domains that correlate and predict mathematics performance in high-performing students in Singapore. Educational Psychology, 35(6), 747-764. doi: https://doi.org/10.1080/01443410.2013.860221

Lowe, P. A., Grumbein, M. J., \& Raad, J. M. (2011). Examination of the psychometric properties of the Test Anxiety Scale for Elementary Students (TAS-E) scores. Journal of Psychoeducational Assessment, 29(6), 503-514. https://doi.org/10.1177/0734282910395894.

*Luo, W., Aye, K. M., Hogan, D., Kaur, B., \& Chan, M. C. Y. (2013). Parenting behaviors and learning of Singapore students: The mediational role of achievement goals. Motivation and Emotion, 37(2), $274-285$. doi: https://doi.org/10.1007/s11031-012-9303-8

*Lupkowski, A. E., \& Schumacker, R. E. (1991). Mathematics anxiety among talented students. Journal of Youth and Adolescence, 20(6), 563-572. doi: https://doi.org/10.1007/BF01537362

Ma, X. (1999). A meta-analysis of the relationship between anxiety toward mathematics and achievement in mathematics. Journal for Research in Mathematics Education, 30(5), 520-540. https://doi.org/10.2307/ 749772.

Ma, X., \& Kishor, N. (1997). Assessing the relationship between attitude toward mathematics and achievement in mathematics: A meta-analysis. Journal for Research in Mathematics Education, 28(1), 26-47. https://doi. org/10.2307/749662.

Maloney, E. A., Ansari, D., \& Fugelsang, J. A. (2011). The effect of mathematics anxiety on the processing of numerical magnitude. Quarterly Journal of Experimental Psychology, 64(1), 10-16. https://doi.org/10.1080/ 17470218.2010 .533278 .

Maloney, E. A., Risko, E. F., Ansari, D., \& Fugelsang, J. (2010). Mathematics anxiety affects counting but not subitizing during visual enumeration. Cognition, 114(2), 293-297. https://doi.org/10.1016/j.cognition.2009. 09.013.

Maloney, E. A., Waechter, S., Risko, E. F., \& Fugelsang, J. A. (2012). Reducing the sex difference in math anxiety: The role of spatial processing ability. Learning and Individual Differences, 22(3), 380-384. https:// doi.org/10.1016/j.lindif.2012.01.001.

Mammarella, I. C., Caviola, S., \& Dowker, A. (Eds.). (2019). Mathematics anxiety: What is known, and what is still missing. Routledge.

Mammarella, I. C., Donolato, E., Caviola, S., \& Giofrè, D. (2018). Anxiety profiles and protective factors: A latent profile analysis in children. Personality and Individual Differences, 124, 201-208. https://doi.org/10. 1016/j.paid.2017.12.017.

Mammarella, I. C., Hill, F., Devine, A., Caviola, S., \& Szucs, D. (2015). Math anxiety and developmental dyscalculia: A study on working memory processes. Journal of Clinical and Experimental Neuropsychology, 37(8), 878-887. https://doi.org/10.1080/13803395.2015.1066759.

Marsh, H. W., \& Yeung, A. S. (1998). Longitudinal structural equation models of academic self-concept and achievement: Gender differences in the development of math and English constructs. American Educational Research Journal, 35(4), 705-738. https://doi.org/10.3102/00028312035004705.

*Marsh, H. W., Pekrun, R., Parker, P. D., Murayama, K., Guo, J., Dicke, T., \& Lichtenfeld, S. (2017). Long-term positive effects of repeating a year in school: Six-year longitudinal study of self-beliefs, anxiety, social relations, school grades, and test scores. Journal of Educational Psychology, 109(3), 425-438. doi: https:// doi.org/10.1037/edu0000144

*Mavilidi, M. F., Hoogerheide, V., \& Paas, F. (2014). A quick and easy strategy to reduce test anxiety and enhance test performance. Applied Cognitive Psychology, 28(5), 720-726. doi: https://doi.org/10.1002/acp.3058

McDonald, A. S. (2001). The prevalence and effects of test anxiety in school children. Educational Psychology, 21(1), 89-101. https://doi.org/10.1080/01443410020019867.

*Meece, J. L., \& Wigfield, A. (1990). Predictors of math anxiety and its influence on young adolescents' course enrollment intentions and performance in mathematics. Expectancy-value motivation and STEM choices View project Social Executive Functioning View project. Journal of Educational Psychology. doi: https:// doi.org/10.1037/0022-0663.82.1.60

*Merritt, W. P. (2011). Exploring math anxiety as it relates to math achievement, gender, and race (Publication No. 3487164; Vol. 73, Numeri 3-A, pag. 943) [Doctoral dissertation, Mississippi State University]. ProQuest Dissertations Publishing. https://www.proquest.com/openview/e6a2aa14ba1d1006da5931b32cc63b60/1? pq-origsite $=$ gscholar\&cbl $=18750$.

*Metallidou, P., \& Vlachou, A. (2007). Motivational beliefs, cognitive engagement, and achievement in language and mathematics in elementary school children. International Journal of Psychology, 42(1), 215. doi: https://doi.org/10.1080/00207590500411179

*Mevarech, Z. R., Silber, O., \& Fine, D. (1991). Learning with computers in small groups: Cognitive and affective outcomes. Journal of Educational Computing Research, 7(2), 233-243. doi: https://doi.org/10. 2190/brcj-p9k5-9e1d-2alc 
*Miller, H., \& Bichsel, J. (2004). Anxiety, working memory, gender, and math performance. Personality and Individual Differences, 37(3), 591-606. doi: https://doi.org/10.1016/j.paid.2003.09.029

Moore, A. M., Rudig, N. O., \& Ashcraft, M. H. (2015). Affect, motivation, working memory, and mathematics. In R. C. Kadosh \& A. Dowker (Eds.), The Oxford handbook of numerical cognition (pp. 933-952). Oxford University Press.

*Morony, S., Kleitman, S., Lee, Y. P., \& Stankov, L. (2013). Predicting achievement: Confidence vs selfefficacy, anxiety, and self-concept in Confucian and European countries. International Journal of Educational Research, 58, 79-96. doi: https://doi.org/10.1016/j.ijer.2012.11.002

*Morsanyi, K., Busdraghi, C., \& Primi, C. (2014). Mathematical anxiety is linked to reduced cognitive reflection: A potential road from discomfort in the mathematics classroom to susceptibility to biases. Behavioral and Brain Functions, 10(1), 1-13. doi: https://doi.org/10.1186/1744-9081-10-31

*Mousavi, M., Haghshenas, H., \& Alishahi, M. J. (2008). Effect of gender, school performance and school type on test anxiety among Iranian adolescents. Iranian Red Crescent Medical Journal, 10, 4-7.

Mueller, C. M., \& Dweck, C. S. (1998). Praise for intelligence can undermine children's motivation and performance. Journal of Personality and Social Psychology, 75(1), 33-52. https://doi.org/10.1037/00223514.75.1.33.

Namkung, J. M., Peng, P., \& Lin, X. (2019). The relation between mathematics anxiety and mathematics performance among school-aged students: A meta-analysis. Review of Educational Research, 89(3), 459496. https://doi.org/10.3102/0034654319843494.

Newstead, K. (1998). Aspects of children's mathematics anxiety. Educational Studies in Mathematics, 36(1), 5371. https://doi.org/10.1023/A:1003177809664.

*Ng, E. L., \& Lee, K. (2015). Effects of trait test anxiety and state anxiety on children's working memory task performance. Learning and Individual Differences, 40, 141-148. doi: https://doi.org/10.1016/j.lindif.2015.04.007

$\mathrm{Ng}$, E., \& Lee, K. (2010). Children's task performance under stress and non-stress conditions: A test of the processing efficiency theory. Cognition and Emotion, 24(7), 1229-1238. https://doi.org/10.1080/ 02699930903172328.

*Novak, E., \& Tassell, J. (2015). Using video game play to improve education-majors' mathematical performance: An experimental study. Computers in Human Behavior, 53, 124-130. doi: https://doi.org/10.1016/j. chb.2015.07.001

Núñez-Peña, M. I., Suárez-Pellicioni, M., \& Bono, R. (2013). Effects of math anxiety on student success in higher education. International Journal of Educational Research, 58, 36-43. https://doi.org/10.1016/j.ijer. 2012.12.004.

Nyroos, M., Korhonen, J., Peng, A., Linnanmäki, K., Svens-Liavåg, C., Bagger, A., \& Sjöberg, G. (2015). Cultural and gender differences in experiences and expression of test anxiety among Chinese, Finnish, and Swedish grade 3 pupils. International Journal of School and Educational Psychology, 3(1), 37-48. https:// doi.org/10.1080/21683603.2014.915773.

Organization for Economic Cooperation and Development. (2013). PISA 2012 assessment and analytical framework: Mathematics, reading, science, problem solving and financial literacy. OECD Publishing.

Organization for Economic Cooperation and Development. (2016). PISA 2015 results in focus. OECD Publishing.

*Ottmar, E., \& Landy, D. (2017). Concreteness fading of algebraic instruction: Effects on learning. Journal of the Learning Sciences, 26(1), 51-78. doi: https://doi.org/10.1080/10508406.2016.1250212

Owens, M., Stevenson, J., Hadwin, J. A., \& Norgate, R. (2012). Anxiety and depression in academic performance: An exploration of the mediating factors of worry and working memory. School Psychology International, 33(4), 433-449. https://doi.org/10.1177/0143034311427433.

*Owens, M., Stevenson, J., Norgate, R., \& Hadwin, J. A. (2008). Processing efficiency theory in children: Working memory as a mediator between trait anxiety and academic performance. Anxiety, Stress \& Coping, 21(4), 417-430. doi: https://doi.org/10.1080/10615800701847823

*Paechter, M., Macher, D., Martskvishvili, K., Wimmer, S., \& Papousek, I. (2017). Mathematics anxiety and statistics anxiety. Shared but also unshared components and antagonistic contributions to performance in statistics. Frontiers in Physiology, 8(JUL). doi: 10.3389/fpsyg.2017.01196

*Pajares, F. (1996). Self-efficacy beliefs and mathematical problem-solving of gifted students. Contemporary educational psychology, 21(4), 325-344. doi: https://doi.org/10.1006/ceps.1996.0025

Pajares, F. (2005). Gender differences in mathematics self-efficacy beliefs. In A. M. Gallagher \& J. C. Kaufman (Eds.), Gender differences in mathematics: An integrative psychological approach (pp. 294-315). Cambridge University Press.

*Pajares, F., \& Graham, L. (1999). Self-efficacy, motivation constructs, and mathematics performance of entering middle school students. Contemporary Educational Psychology, 24(2), 124-139. doi: https://oi. org/10.1006/ceps.1998.0991 
*Pajares, F., \& Kranzler, J. (1995). Self-efficacy beliefs and general mental ability in mathematical problemsolving. Contemporary Educational Psychology, 20(4), 426-443. doi: https://doi.org/10.1006/ceps.1995. 1029

*Pedro, J. D., Wolleat, P., Fennema, E., \& Becker, A. D. (1981). Election of high school mathematics by females and males: Attributions and attitudes. American Educational Research Journal, 18(2), 207-218. doi: https:// doi.org/10.3102/00028312018002207

*Peixoto, F., Sanches, C., Mata, L., \& Monteiro, V. (2017). "How do you feel about math?": Relationships between competence and value appraisals, achievement emotions and academic achievement. European Journal of Psychology of Education, 32(3), 385-405.

Pekrun, R., \& Bühner, M. (2014). Self-report measures of academic emotions. In R. Pekrun \& L. LinnenbrinkGarcia (Eds.), International handbook of emotions in education (pp. 561-579). Taylor \& Francis.

Pekrun, R., Goetz, T., Perry, R. P., Kramer, K., Hochstadt, M., \& Molfenter, S. (2004). Beyond test anxiety: Development and validation of the Test Emotions Questionnaire (TEQ). Anxiety, Stress and Coping, 17(3), 287-316. https://doi.org/10.1080/10615800412331303847.

*Pekrun, R., Lichtenfeld, S., Marsh, H. W., Murayama, K., \& Goetz, T. (2017). Achievement emotions and academic performance: Longitudinal models of reciprocal effects. Child Development, 88(5), 1653-1670. doi: https://doi.org/10.1111/cdev.12704

*Peng, Y., Hong, E., \& Mason, E. (2014). Motivational and cognitive test-taking strategies and their influence on test performance in mathematics. Educational Research and Evaluation, 20(5), 366-385. doi: https://doi.org/ $10.1080 / 13803611.2014 .966115$

Peng, P., Namkung, J., Barnes, M., \& Sun, C. (2016). A meta-analysis of mathematics and working memory: Moderating effects of working memory domain, type of mathematics skill, and sample characteristics. Journal of Educational Psychology, 108, 455-473. https://doi.org/10.1037/edu0000079.

*Perry, S. M., Catapano, M., \& Ramon, O. G. (2016). Teaching, academic achievement, and attitudes toward mathematics in the United States and Nigeria. Journal for Leadership and Instruction, 15(2), 5-12.

*Pizzie, R. G. (2018). Cognition, calculation, and emotion regulation: building an effective math anxiety intervention in the lab and in the classroom (Publication No. 10822585) [Doctoral dissertation, Dartmouth College]. ProQuest Dissertations Publishing. https://www.proquest.com/openview/ 276570a958d9af5c77772251c4380f93/1?pq-origsite=gscholar\&cbl=18750.

*Prieto, G., \& Delgado, A. R. (2007). Requests for reprints should be sent to measuring math anxiety (in Spanish) with the Rasch rating scale model. Journal of applied measurement, 8(2), 149

*Primi, C., Donati, M. A., \& Chiesi, F. (2018). The role of statistics anxiety in learning probability. In C. Batanero \& E. J. Chernoff (Eds.), Teaching and learning stochastics (pp. 145-157): Springer Cham.doi: https://doi.org/10.1007/978-3-319-72871-1_9

Putwain, D. W. (2007). Test anxiety in UK schoolchildren: Prevalence and demographic patterns. British Journal of Educational Psychology, 77(3), 579-593. https://doi.org/10.1348/000709906X161704.

Putwain, D. W. (2008). Test anxiety and GCSE performance: The effect of gender and socio-economic background. Educational Psychology in Practice, 24(4), 319-334. https://doi.org/10.1080/ 02667360802488765.

*Putwain, D. W., Becker, S., Symes, W., \& Pekrun, R. (2018). Reciprocal relations between students' academic enjoyment, boredom, and achievement over time. Learning and Instruction, 54, 73-81. doi: https://doi.org/ 10.1016/j.learninstruc.2017.08.004

*Putwain, D. W., Connors, L., \& Symes, W. (2010a). Do cognitive distortions mediate the test anxietyexamination performance relationship? Educational Psychology, 30(1), 11-26. doi: https://oi.org/10. 1080/01443410903328866

Putwain, D. W., \& Daly, A. L. (2014). Test anxiety prevalence and gender differences in a sample of English secondary school students. Educational Studies, 40(5), 554-570. https://doi.org/10.1080/03055698.2014.953914.

*Putwain, D. W., Daly, A. L., Chamberlain, S., \& Sadreddini, S. (2015). Academically buoyant students are less anxious about and perform better in high-stakes examinations. British Journal of Educational Psychology, 85(3), 247-263. doi: https://doi.org/10.1111/bjep.12068

*Putwain, D. W., Nicholson, L. J., Connors, L., \& Woods, K. (2013). Resilient children are less test anxious and perform better in tests at the end of primary schooling. Learning and Individual Differences, 28, 41-46. doi: https://doi.org/10.1016/j.lindif.2013.09.010

*Putwain, D., \& Symes, W. (2011). Perceived fear appeals and examination performance: Facilitating or debilitating outcomes?. Learning and Individual Differences, 21(2), 227-232.

Putwain, D. W., Woods, K. A., \& Symes, W. (2010b). Personal and situational predictors of test anxiety of students in post-compulsory education. British Journal of Educational Psychology, 80(1), 137-160. https:// doi.org/10.1348/000709909X466082. 
Raghubar, K. P., Barnes, M. A., \& Hecht, S. A. (2010). Working memory and mathematics: A review of developmental, individual difference, and cognitive approaches. Learning and individual differences, 20(2), 110-122. https://doi.org/10.1016/j.lindif.2009.10.005.

*Rahafar, A., Maghsudloo, M., Farhangnia, S., Vollmer, C., \& Randler, C. (2015). Academic achievement is predicted by gender, test anxiety, and conscientiousness; an investigation of moderating role of gender and chronotype. Chronobiology International, 33(1), 1-9.

* Ramirez, G. (2017). Motivated forgetting in early mathematics: A proof-of-concept study. Frontiers in Psychology, 8(DEC). doi: https://doi.org/10.3389/fpsyg.2017.02087

*Ramirez, G., Chang, H., Maloney, E. A., Levine, S. C., \& Beilock, S. L. (2016). On the relationship between math anxiety and math achievement in early elementary school: The role of problem solving strategies. Journal of Experimental Child Psychology, 141, 83-100. doi: https://doi.org/10.1016/j.jecp.2015.07.014

Ramirez, G., Gunderson, E. A., Levine, S. C., \& Beilock, S. L. (2013). Math anxiety, working memory, and math achievement in early elementary school. Journal of Cognition and Development, 14(2), 187-202. https://doi. org/10.1080/15248372.2012.664593.

*Reali, F., Jiménez-Leal, W., Maldonado-Carreño, C., Devine, A., \& Szücs, D. (2016). Examining the link between math anxiety and math performance in Colombian students. Revista Colombiana de Psicologia, 25(2), 369-379. doi: https://doi.org/10.15446/rcp.v25n2.54532

*Recber, S., Isiksal, M., \& Koç, Y. (2018). Investigando la autoeficacia, la ansiedad, las actitudes y los logros de las matemáticas con respecto al género y el tipo de escuela. Anales de Psicologia, 34(1), 41-51. doi: https:// doi.org/10.6018/analesps.34.1.229571

*Roick, J., \& Ringeisen, T. (2017). Self-efficacy, test anxiety, and academic success: A longitudinal validation. International Journal of Educational Research, 83, 84-93. doi: https://doi.org/10.1016/j.ijer.2016.12.006

Roos, A. L., Goetz, T., Voracek, M., Krannich, M., Bieg, M., Jarrell, A., \& Pekrun, R. (2020). Test anxiety and physiological arousal: A systematic review and meta-analysis. Educational Psychology Review, 1-40. https://doi.org/10.1007/s10648-020-09543-Z.

Rosseel, Y. (2012). lavaan: an R package for structural equation modeling and more Version 0.5-12 (BETA). Retrieved from http://cran.r-project.org/.

Rubinsten, O., Bialik, N., \& Solar, Y. (2012). Exploring the relationship between math anxiety and gender through implicit measurement. Frontiers in Human Neuroscience, 6, 279. https://doi.org/10.3389/fnhum. 2012.00279 .

Sarason, I. G., \& Sarason, B. R. (1990). Test anxiety. In H. Leitenberg (Ed.), Handbook of social and evaluation anxiety (pp. 475-495). Springer Scinces+Bussiness Media. https://doi.org/10.1007/978-1-4899-2504-6_16.

*Satake, E., \& Amato, P. P. (1995). Mathematics anxiety and achievement among Japanese elementary school students. Educational and Psychological Measurement, 55(6), 1000-1007. doi: https://doi.org/10.1177/ 0013164495055006009

*Savage, K. L. (2016). Mathematical motivation beliefs: A study on the influences of the mathematical motivation beliefs of students in a predominantly African American environment in Mississippi (Publication No. 10242162) [Doctoral dissertation, Mississippi State University]. ProQuest Dissertations Publishing. https://www.proquest.com/docview/1858815062/57A3C46766C9417CPQ/1 ?accountid=13050.

Scherer, R., \& Siddiq, F. (2015). The big-fish-little-pond-effect revisited: do different types of assessments matter? Computers \& Education, 80, 198-210. https://doi.org/10.1016/j.compedu.2014.09.003.

*Schillinger, F. L., Vogel, S. E., Diedrich, J., \& Grabner, R. H. (2018). Math anxiety, intelligence, and performance in mathematics: Insights from the German adaptation of the Abbreviated Math Anxiety Scale (AMAS-G). Learning and Individual Differences, 61, 109-119. doi: https://doi.org/10.1016/j.lindif.2017.11.014

Schneider, M., Beeres, K., Coban, L., Merz, S., Susan Schmidt, S., Stricker, J., \& De Smedt, B. (2017). Associations of non-symbolic and symbolic numerical magnitude processing with mathematical competence: A meta-analysis. Developmental Science, 20(3), e12372. https://doi.org/10.1111/desc.12372.

Schnell, K., Tibubos, A. N., Rohrmann, S., \& Hodapp, V. (2013). Test and math anxiety: A validation of the German Test Anxiety Questionnaire. Polish Psychological Bulletin, 2(44), 193-200. https://doi.org/10.2478/ ppb-2013-0022.

Schrank, F. A., Mather, N., \& McGrew, K. S. (2014). Woodcock-Johnson IV Tests of Achievement. Riverside. Schwarzer, G., Carpenter, J. R., \& Rücker, G. (2015). Meta-analysis with R. Springer.

Segool, N. K., Carlson, J. S., Goforth, A. N., Von der Embse, N., \& Barterian, J. A. (2013). Heightened test anxiety among young children: Elementary school students' anxious responses to high-stakes testing. Psychology in the Schools, 50(5), 489-499. https://doi.org/10.1002/pits.21689.

Seipp, B. (1991). Anxiety and academic performance: A meta-analysis of findings. Anxiety Research, 4(1), 2741. https://doi.org/10.1080/08917779108248762.

*Sheller, C. V. (2008). American and Russian Mathematics Self-efficacy: A Comparison (Publication No. 3326013) [Doctoral dissertation, Seattle Pacific University]. ProQuest Dissertations Publishing. https:// www.proquest.com/openview/7c0f15794f83eafcf807532b4532abb5/1?pq-origsite=gscholar\&cbl=18750. 
*Siebers, W. M. (2015). Relationship between math anxiety and student achievement of middle school students, The (Publication No. 0053A_12903) [Doctoral dissertation, Colorado State University]. Mountain Scholar. https://mountainscholar.org/handle/10217/166940.

Sieber, J. E., O’Neil Jr., H. E., \& Tobias, S. (1977). Anxiety, learning and instruction. Erlbaum.

Siegler, R. S., \& Booth, J. L. (2005). Development of numerical estimation. In J. D. Campbell (Ed.), Handbook of mathematical cognition (pp. 197-212). Psychology Press.

Sirriyeh, R., Lawton, R., Armitage, G., Gardner, P., \& Ferguson, S. (2012). Safety subcultures in health-care organizations and managing medical error. Health Services Management Research, 25(1), 16-23. https://doi. org/10.1258/hsmr.2011.011018.

*Skaalvik, E. M. (2018). Mathematics anxiety and coping strategies among middle school students: Relations with students' achievement goal orientations and level of performance. Social Psychology of Education, 21(3), 709-723. doi: https://doi.org/10.1007/s11218-018-9433-2

*Skagerlund, K., Lind, T., Strömbäck, C., Tinghög, G., \& Västfjäll, D. (2018). Financial literacy and the role of numeracy-How individuals' attitude and affinity with numbers influence financial literacy. Journal of Behavioral and Experimental Economics , 74, 18-25. doi: https://doi.org/10.1016/j.socec.2018.03.004

*Solazzo, L. A. (2008). The role of gender, cognition, anxiety, and competence beliefs in predicting mathematics achievement (Publication No. 3303095) [Doctoral dissertation, Fordham University]. ProQuest Dissertations Publishing. https://www.proquest.com/openview/fc91af93f88f92753253f7b208c88d08/1 ?pq-origsite= gscholar\&cbl=18750\&diss $=y$.

*Soni, A., \& Kumari, S. (2017). The role of parental math anxiety and math attitude in their children's math achievement. International Journal of Science and Mathematics Education, 15(2), 331-347. doi: https://oi. org/10.1007/s10763-015-9687-5

*Sorvo, R., Koponen, T., Viholainen, H., Aro, T., Räikkönen, E., Peura, P., ... Aro, M. (2017). Math anxiety and its relationship with basic arithmetic skills among primary school children. British Journal of Educational Psychology, 87(3), 309-327. doi: https://doi.org/10.1111/bjep.12151

*Spinath, B., Harald Freudenthaler, H., \& Neubauer, A. C. (2010). Domain-specific school achievement in boys and girls as predicted by intelligence, personality and motivation. Personality and Individual Differences, 48(4), 481-486. doi: https://doi.org/10.1016/j.paid.2009.11.028

*Spybrook, J. (2008). The relationship among working memory, mathematics anxiety, and mathematics achievement in developmental mathematics courses in community college (Publication No. 3345281) [Doctoral dissertation, The University of San Francisco]. ProQuest Dissertations Publishing. https:/www.proquest. com/openview/a576723f6d4595a7dce3ea82e8cd38d0/1?cbl=18750\&pq-origsite=gscholar.

*Stankov, L., \& Lee, J. (2014). Quest for the best non-cognitive predictor of academic achievement. Educational Psychology, 34(1), 1-8. doi: https://doi.org/10.1080/01443410.2013.858908

*Stankov, L., Lee, J., Luo, W., \& Hogan, D. J. (2012). Confidence: A better predictor of academic achievement than self-efficacy, self-concept and anxiety? Learning and Individual Differences, 22(6), 747-758. doi: https://doi.org/10.1016/j.lindif.2012.05.013

*Stoet, G., Bailey, D. H., Moore, A. M., \& Geary, D. C. (2016). Countries with higher levels of gender equality show larger national sex differences in mathematics anxiety and relatively lower parental mathematics valuation for girls. PLoS ONE, 11(4). doi: https://doi.org/10.1371/journal.pone.0153857

*Tan, S. (2011). Internalizing symptoms, executive functions, and academic performance (Publication No. 344450) [Doctoral dissertation, Fordham University]. ProQuest Dissertations Publishing. https://www. proquest.com/openview/da1227bedb993cff914f0cdbff5f7518/1?cbl=18750\&diss=y\&pq-origsite=gscholar.

*Tejada, E. (2011). Classroom social support, math anxiety, method of instruction, and drug-calculation skills of nursing students (Publication No. 3481771) [Doctoral dissertation, Andrews University]. ProQuest Dissertations Publishing. https://www.proquest.com/openview/1187cecfe067eb3bd65cc1e6fb0e897f/1?pqorigsite $=$ gscholar $\& \mathrm{cbl}=18750 \&$ diss $=\mathrm{y}$.

*Thames, A. D., Panos, S. E., Arentoft, A., Byrd, D. A., Hinkin, C. H., \& Arbid, N. (2015). Mild test anxiety influences neurocognitive performance among African Americans and European Americans: Identifying interfering and facilitating sources. Cultural Diversity and Ethnic Minority Psychology, 21(1), 105.

*Timmerman, H. L., Toll, S. W. M., \& Van Luit, J. E. H. (2017). The relation between math self-concept, test and math anxiety, achievement motivation and math achievement in 12 to 14-year-old typically developing adolescents. Psychology, Society and Education, 9(1), 89-103. doi: https://doi.org/10.25115/psye.v9i1.465

*Tocci, C. M., \& Engelhard, G. (1991). Achievement, parental support and gender differences in attitudes toward mathematics. Journal of Educational Research, 84(5), 280-287. doi: https://doi.org/10.1080/00220671. 1991.10886028

*Townsend, C. T. (1991). Math achievement of adult and traditional associate degree nursing students taught via computer-assisted and lecture instruction (Publication No. 9127491) [Doctoral dissertation, The University of Southern Mississippi]. ProQuest Publishing. https://www.proquest.com/openview/ 8b9a25e444def175787fc328fc7becd0/1?pq-origsite=gscholar\&cbl=18750\&diss=y. 
*Trezise, K., \& Reeve, R. A. (2014). Working memory, worry, and algebraic ability. Journal of Experimental Child Psychology, 121(1), 120-136. doi: https://doi.org/10.1016/j.jecp.2013.12.001

*Van der Beek, J. P. J., Van der Ven, S. H. G., Kroesbergen, E. H., \& Leseman, P. P. M. (2017). Self-concept mediates the relation between achievement and emotions in mathematics. British Journal of Educational Psychology, 87(3), 478-495. doi: https://doi.org/10.1111/bjep.12160

*Van Mier, H. I., Schleepen, T. M. J., \& Van den Berg, F. C. G. (2019). Gender differences regarding the impact of math anxiety on arithmetic performance in second and fourth graders. Frontiers in Psychology, 9, 2690. doi: https://doi.org/10.3389/fpsyg.2018.02690

Viechtbauer, W. (2010). Conducting meta-analyses in R with the metafor package. Journal of Statistical Software, 36, 1-48. https://doi.org/10.18637/jss.v036.i03.

Von Der Embse, N., Barterian, J., \& Segool, N. (2013). Test anxiety interventions for children and adolescents: A systematic review of treatment studies from 2000-2010. Psychology in the Schools, 50(1), 57-71. https:// doi.org/10.1002/pits.21660.

von der Embse, N., Jester, D., Roy, D., \& Post, J. (2018). Test anxiety effects, predictors, and correlates: A 30year meta-analytic review. Journal of Affective Disorders, 227, 483-493. https://doi.org/10.1016/j.jad.2017. 11.048 .

von der Embse, N. P., \& Putwain, D. W. (2015). Examining the context of instruction to facilitate student success. School Psychology International, 36(6), 552-558. https://doi.org/10.1177/0143034315612144.

*Vukovic, R. K., Kieffer, M. J., Bailey, S. P., \& Harari, R. R. (2013a). Mathematics anxiety in young children: Concurrent and longitudinal associations with mathematical performance. Contemporary educational psychology, 38(1), 1-10.

*Vukovic, R. K., Roberts, S. O., \& Green Wright, L. (2013b). From parental involvement to children's mathematical performance: The role of mathematics anxiety. Early Education and Development, 24(4), 446-467. doi: https://doi.org/10.1080/10409289.2012.693430

*Wang, Z., Hart, S. A., Kovas, Y., Lukowski, S., Soden, B., Thompson, L. A., ... \& Petrill, S. A. (2014). Who is afraid of math? Two sources of genetic variance for mathematical anxiety. Journal of child psychology and psychiatry, 55(9), 1056-1064. doi: https://doi.org/10.1111/jcpp.12224

*Wang, Z., Lukowski, S. L., Hart, S. A., Lyons, I. M., Thompson, L. A., Kovas, Y., ... \& Petrill, S. A. (2015). Is math anxiety always bad for math learning? The role of math motivation. Psychological science, 26(12), 1863-1876. doi: https://doi.org/10.1177/2F0956797615602471

*Wang, Z., Shakeshaft, N., Schofield, K., \& Malanchini, M. (2018). Anxiety is not enough to drive me away: A latent profile analysis on math anxiety and math motivation. PLOS ONE, 13(2). doi: https://doi.org/10.1371/ journal.pone.0192072

*Watts, B. K. (2011). Relationships of mathematics anxiety, mathematics self-efficacy and mathematics performance on adult basic education students (Publication No. 3449398) [Doctoral dissertation, Capella University]. ProQuest Dissertations Publishing. https://www.proquest.com/docview/862498506?pqorigsite $=$ gscholar $\&$ fromopenview $=$ true.

Whitaker Sena, J. D., Lowe, P. A., \& Lee, S. W. (2007). Significant predictors of test anxiety among students with and without learning disabilities. Journal of Learning Disabilities, 40(4), 360-376. https://doi.org/10. $1177 / 00222194070400040601$.

Wigfield, A., \& Meece, J. L. (1988). Math anxiety in elementary and secondary school students. Journal of Educational Psychology, 80(2), 210. https://doi.org/10.1037/0022-0663.80.2.210.

*Williams, J. E. (1994). Anxiety measurement: Construct validity and test performance. Measurement and Evaluation in Counseling and Development, 27(1), 302-307.

*Witt, M. (2012). The impact of mathematics anxiety on primary school children's working memory. Europe's Journal of Psychology, 8(2), 263-274. doi: https://oi.org/10.5964/ejop.v8i2.458

Wren, D. G., \& Benson, J. (2004). Measuring test anxiety in children: Scale development and internal construct validation. Anxiety, Stress and Coping, 17(3), 227-240. https://doi.org/10.1080/10615800412331292606.

*Wright, E. (2017). Understanding math anxiety in children: deciphering the contribution of math achievement, working memory, and general anxiety (Publication No.4249) [Doctoral dissertation, University of South Carolina]. University of South Carolina Scholar Commons. https://scholarcommons.sc.edu/etd/4249.

*Wu, S. S., Barth, M., Amin, H., Malcarne, V., \& Menon, V. (2012). Math anxiety in second and third graders and its relation to mathematics achievement. Frontiers in Psychology, 3, 162. doi: https://doi.org/10.3389/ fpsyg.2012.00162

*Wu, S. S., Chen, L., Battista, C., Smith Watts, A. K., Willcutt, E. G., \& Menon, V. (2017). Distinct influences of affective and cognitive factors on children's non-verbal and verbal mathematical abilities. Cognition, 166, 118-129. doi: https://doi.org/10.1016/j.cognition.2017.05.016

*Wu, S. S., Willcutt, E. G., Escovar, E., \& Menon, V. (2014). Mathematics achievement and anxiety and their relation to internalizing and externalizing behaviors. Journal of Learning Disabilities, 47(6), 503-514. doi: https://doi.org/10.1177/0022219412473154 
*Yáñez-Marquina, L., \& Villardón-Gallego, L. (2017). Math anxiety, a hierarchical construct: Development and validation of the scale for assessing math anxiety in secondary education. Ansiedad y Estrés, 23(2-3), 59-65. doi: https://doi.org/10.1016/j.anyes.2017.10.001

*Yildirim, S. (2012). Teacher support, motivation, learning strategy use, and achievement: A multilevel mediation model. Journal of Experimental Education, 80(2), 150-172. doi: https://doi.org/10.1080/ 00220973.2011 .596855

Yu, J., Downes, P. E., Carter, K. M., \& O’Boyle, E. H. (2016). The problem of effect size heterogeneity in metaanalytic structural equation modeling. Journal of Applied Psychology, 101, 1457-1473. https://doi.org/10. 1037/ap10000141.

Zeidner, M. (1990). Does test anxiety bias scholastic aptitude test performance by gender and sociocultural group? Journal of Personality Assessment, 55(1-2), 145-160. https://doi.org/10.1080/00223891.1990. 9674054.

Zeidner, M. (2007). Test anxiety in educational contexts. Concepts, findings, and future directions. In P. A. Schutz \& R. Pekrun (Eds.), Emotion in education (pp. 165-184). New York: Academic Press. https://doi. org/10.1016/B978-012372545-5/50011-3.

Zeidner, M. (2014). Test anxiety. In P. Emmelkamp \& T. Ehring (Eds.), Wiley handbook of anxiety disorders (pp. 581-595). John Wiley.

Zeidner, M., \& Schleyer, E. J. (1999). The big-fish-little-pond effect for academic self-concept, test anxiety, and school grades in gifted children. Contemporary Educational Psychology, 24(4), 305-329. https://doi.org/10. 1006/ceps. 1998.0985.

*Zirk-Sadowski, J., Lamptey, C., Devine, A., Haggard, M., \& Szücs, D. (2014). Young-age gender differences in mathematics mediated by independent control or uncontrollability. Developmental Science, 17(3), 366-375. doi: https://doi.org/10.1111/desc. 12126

Publisher's Note Springer Nature remains neutral with regard to jurisdictional claims in published maps and institutional affiliations.

\section{Affiliations}

\section{Sara Caviola ${ }^{1,2}$ Enrico Toffalini ${ }^{3}$ - David Giofrè ${ }^{4}$ Jessica Mercader Ruiz ${ }^{5}$. Dénes Szűcs ${ }^{6}$ - Irene C. Mammarella ${ }^{1}$}

1 Department of Developmental and Social Psychology, University of Padova, Via Venezia 8, 35131 Padova, Italy

2 School of Psychology, University of Leeds, Leeds LS2 9JT, UK

3 Department of General Psychology, University of Padova, Padova, Italy

4 Department of Educational Sciences, University of Genoa, Genoa, Italy

5 Developmental and Educational Psychology, Jaume I University, Valencia, Spain

6 Centre for Neuroscience in Education, Department of Psychology, University of Cambridge, Cambridge, UK 